\title{
Dynamics of Income Inequality and Welfare in Latvia in the Late 1990s ${ }^{1}$
}

\author{
By \\ Hippolyte Fofack* and Celestin Monga**
}

\begin{abstract}
This paper analyzes the dynamics of poverty and income inequality during the recovery phase of the transition that characterized the Republic of Latvia in the late 1990s. Despite a continued rise in income inequality, empirical evidence suggests an improvement in living standards, owing largely to a significant surge in per capita income growth, particularly in urban areas. In a context of rising income inequality and widening urban-rural income and poverty gaps, the benefits of growth were not equally distributed, and poverty persisted in a number of regions (particularly the regions of Latgale and Vitzeme) and among some socioeconomic groups (particularly households deriving their main income from social benefits). In addition to income inequality and asset endowments, poverty appears to be highly correlated with a number of labor market-related variables, particularly unemployment, suggesting that the labor market could be an important transmission channel from growth to poverty. However, though positive, the association between poverty and unemployment is non linear, especially in urban areas, where the labor market and demand are the most important channels of transmission through which growth and macroeconomic development affect household income and living standards.
\end{abstract}

JEL Classifications: C25; D31; E24; I32

Keywords: income inequality-driven poverty reduction deficit, poverty incidence curve, urbanrural employment gaps, urban-rural poverty gaps, urban-rural predicted probability gaps.

World Bank Policy Research Working Paper 3336, June 2004

The Policy Research Working Paper Series disseminates the findings of work in progress to encourage the exchange of ideas about development issues. An objective of the series is to get the findings out quickly, even if the presentations are less than fully polished. The papers carry the names of the authors and should be cited accordingly. The findings, interpretations, and conclusions expressed in this paper are entirely those of the authors. They do not necessarily represent the view of the World Bank, its Executive Directors, or the countries they represent. Policy Research Working Papers are available online at http://econ.worldbank.org.

\footnotetext{
$1 *$ World Bank Institute and **World Bank ECA Region. The authors gratefully acknowledge the support and collaboration of the Latvian Central Statistics Bureau, and particularly the support provided by Mr. Edmunds Vaskis, the Director of the Social Statistics Department. We would like to thank Andrejs Jakobsons, Xiao Ye, Raj R. Nallari, Branko Milanovic, Uwe Deichmann, Nanak Kakwani and Olivier-Jean Blanchard and Latvian authorities for their useful assistance and comments, and Pierre-Richard Agénor and Bernard Funck for guidance and support on various aspects of this study.
} 


\section{Introduction}

The last World Bank Poverty Assessment in Latvia, published in 2000, focused on income inequality and distribution of welfare across geographical regions, socioeconomic groups and age profile. That report suggested a declining trend in income inequality across most transition economies throughout the second half of the 1990s (World Bank [2000a]). For instance, in the Russia Federation, where the highest increase was recorded, the Gini coefficient, a standard measure of income inequality, increased by about $85 \%$, from 26 to $48 \%$ between 1990 and 1995, before declining to $47 \%$ in the late $1990 \mathrm{~s}$. This consistent and declining trend in income inequality across most transition economies represented a significant shift and reversal from the earlier phase of the transitional period, when income inequality increased dramatically. In the case of Latvia, however, income inequality rose from 24 to $31 \%$ between 1990 and 1995 (representing a 31\% increase) and then stabilized at about 32\% between 1995 and 1997, suggesting a tapering off rather a than a reversal trend. With this leveling off, the magnitude of income inequality remains significantly above the levels recorded in the pre-transition era, suggesting a persistence of income disparities in Latvia.

The Poverty Assessment identified unequal distribution of assets, leakages and bias in the allocation of social transfers as possible determinants of the resilience of income inequality in Latvia (World Bank [2000a]). It also singled out income inequality and leakages in public spending allocation to explain the high level of poverty incidence, established at about $20 \%$ in 1997. During that period, significant differences were also observed across geographical regions and socioeconomic groups. However, despite the rapid surge of urban poverty, partly associated with relatively high rates of unemployment in the post-transition period, the urban-rural poverty gap remains large. While less than $11 \%$ of urban households were classified as poor, poverty incidence rates exceeding 30\% were common in rural areas. Moreover, significant differences existed across geographical regions, with Latgale being the poorest region (Gassmann [1998], World Bank [2000a]). These differences were even more pronounced across socioeconomic groups, with poverty incidence gaps of more than 20 percentage points between the "wage earners" and the "other social benefits" group, the poorest socioeconomic groups.

With the persistence and continued high rates of poverty incidence, a reflection of a relatively low per capita income, Latvian authorities made the reduction of poverty one of the key objectives and strategic priorities of their medium-term development plan spanning 20032005 . $^{2}$ This development plan identified the pursuit of macroeconomic stability, the implementation of more balanced and sustainable growth and development, the promotion of employment creation, and improvement in the delivery of social services, particularly to the poor and most vulnerable segments of the population, as cornerstones for increasing per capita income and living standards and rapidly achieving poverty reduction objectives (World Bank [2002], IMF [2003]).

\footnotetext{
${ }^{2}$ Indeed, at about US\$3260 per capita income in 2001, Latvia remained well below the graduation threshold required for its accession to the European Union in 2004. For further details on other criteria and requirements for Latvia's accession to the European Union (Zile and Steinbuka [2001], Republic of Latvia [2003]).
} 
In addition to income inequality, the persistence of poverty in Latvia, including in the recovery phase of the transitional period, is also partly explained by a significant drop in output and declining employment and wages following a succession of economic downturns and shocks that punctuated most of the early phase of the transitional period (World Bank [2000b]). These included the banking crisis in 1995, and the Russian economic and financial downturns, which are believed to have had negative spillover effects on Latvia and other Former Soviet Union Countries. ${ }^{3}$ On average, the Latvian economy recorded a negative growth of $-3.6 \%$ during the first part of the transition period between 1992-1995, and grew by $0.2 \%$ between 1992 and 1997 . However, since 1999, more robust economic growth rates have been recorded, with the average over the period 1999-2002 at about 5 percent, reflecting the implementation of structural reforms (World Bank [2002], IMF [2003]).

With the resumption of economic growth in the absence of a distribution neutral assumption, and in a poverty-stricken context, assessing the welfare implications of growth, and in particular differentiating those who are benefiting from those who are not, is key to policymakers. This paper provides the most recent update of the Latvian Poverty Assessment using the 2000 Household Budget Survey (HBS). In particular, it analyzes the dynamics of poverty and income inequality between 1997 and 2000, and investigates the nature and scope of poverty determinants. The results show an increase in household per capita income and expenditures, especially in urban areas, resulting in a relative decline of the headcount index, an illustration of improved living standards in the late 1990s. At the national level, the headcount index fell by 28 percent; the number of poor with per capita income below the poverty line declined from 19.4 to less than $14 \%$. However, the distribution of growth was not uniform, and its benefits were not equally felt across geographical regions and socioeconomic groups. In many areas and socioeconomic groups, poverty remains widespread. This is especially the case for the regions of Latgale and Vidzeme, and the most vulnerable socioeconomic groups whose main source of income is social benefits and assistance. These regions and socioeconomic groups were already identified to be among the poorest in the early phase of the transition and their continued poor ranking may illustrate the stability over time of the poverty map in the absence of a significant pro-poor distributional shift in the recovery phase of the transitional period.

Indeed, income inequality persisted and even increased in a number of regions and sectors of employment, contrasting with the declining trends in the mid-1990s. The Gini coefficient increased by $8 \%$, from 34 to $37 \%$. The relatively skewed nature of the growth process may partly explain the persistence of poverty, particularly in the most vulnerable socioeconomic groups and geographical regions. This paper also identifies a number of other correlates of poverty in Latvia, including spatial location of households correlated with socioeconomic groups, household dependency ratio, housing amenities, income and assets inequality, household ownership of real and financial assets, and the unemployment ratio. However, though poverty is positively correlated with unemployment ratio, the relationship is not linear; and the non linearity is more pronounced in urban areas.

The remainder of this paper is organized as follows. The next section focuses on the dynamics of income inequality, and the impact of social transfers on the scope and trend of

\footnotetext{
${ }^{3}$ Indeed the economic crisis witnessed right in the aftermath of the post-socialism era was profound, and was characterized by a significant drop in output, with levels comparable to those recorded during the Great Depression in 1930s (World Bank [2000b]).
} 
income inequality. Section III focuses on the dynamics of poverty and its correlates, with emphasis on the distribution of welfare across geographical regions and socioeconomic groups. Section IV investigates the determinants of poverty using probit analysis. Section V provides concluding remarks and policy implications.

\section{Dynamics of Income Inequality in Latvia}

This Section provides a trend analysis of income inequality and poverty using two Household Budget Surveys carried out by the Latvian Central Statistics Bureau in 1997 and 2000. These surveys are very similar in the scope of data collection, sampling design and coverage. They are nationally representative and the sample selection uses a multi-stage stratified random sampling in both designs. The questionnaires are standardized and collect individual and household level information on a relatively large sample: 7,881 households in the first round, and about 3,846 in the second. This relatively large coverage allows a spatial analysis of welfare and income inequality, which reflects the country's five main geographic regions and key socioeconomic groups. ${ }^{4}$ The similarity in the sampling and standardized questionnaire design also facilitates welfare inferences over time.

The Latvian Household Budget Survey data is of excellent quality, a necessary attribute for robust estimation and welfare inference over time. In particular, these surveys collect exhaustive information on non money metric and money metric variables, and especially household expenditures and income, including state and local transfers, income from own property (real estate, interests and dividends), and unemployment benefits and compensation. ${ }^{5}$ The quality of the data is partly illustrated by the consistency in the trend of welfare estimates from income and expenditure aggregates. ${ }^{6}$ Table 1 provides point estimates for measures of central tendency, variance and income inequality over the two reference periods. These statistics are based on the monthly household per capita expenditures estimated at the national and regional levels. Table 1 in annex 1 provides similar estimates for measures of central tendency, variance and income inequality over the same reference periods, based on the monthly household per capita income.

At 74 lats, the mean per capita expenditure is slightly above the nationally accepted minimum wage established at 70 lats. This measure of central tendency, along with the median per capita household expenditure aggregate, is consistently higher than the incomebased estimates, reflecting the relatively low nonsampling errors. ${ }^{7}$ Though these surveys

\footnotetext{
${ }^{4}$ The main geographic regions include the Riga region, Kurzeme (Western region), Vidzeme (Central region), Zemgale (Northern region), and Latgale (Eastern region). Similarly, there are 5 key socioeconomic groups, including Wage and Salary Earners, Entrepreneurs and Self-employed, Farmers, Pensioners, and Other Households.

${ }^{5}$ The good quality of the data is also tributary of the nature of the survey: aggregate distributions of household expenditure from more comprehensive surveys such as Household Budget Surveys, are also subject to low bias and non sampling errors because the relatively high frequency of visits to households increases recall and reduces underreporting.

${ }^{6}$ The quality of income data is reminiscent of the socialist era, where most income sources were under the direct control of the state, and data collection agencies could verify reported income at the sources. The implicit control system limited the prospects for under-reporting, which is likely to grow with the rise of private sector income.

${ }^{7}$ Historically, this bias has been considerably higher in Sub-Saharan African countries, particularly when income data is collected on a single visit to households in the context of the implementation of Household Priority Surveys, for instance.
} 
collect exhaustive and reliable information on household income and expenditures, we use the latter as the measure of welfare. In addition to the empirical argument, there are strong theoretical reasons supporting the use of expenditure over income, even in the presence of more comprehensive surveys with extensive information on income and expenditure (Deaton and Muellbauer [1980]). ${ }^{8}$

Table 1: Per Capita Household Expenditure-Based Summary Statistics and Income Inequality Measures (in LVL)

\begin{tabular}{lllllll}
\hline & \multicolumn{3}{c}{ National Level } & \multicolumn{2}{c}{ Urban Area } & \multicolumn{2}{c}{ Rural Area } \\
\hline Point Estimates & $\mathbf{1 9 9 7}$ & $\mathbf{2 0 0 0}$ & $\mathbf{1 9 9 7}$ & $\mathbf{2 0 0 0}$ & $\mathbf{1 9 9 7}$ & $\mathbf{2 0 0 0}$ \\
Mean & 58.11 & 74.06 & 60.62 & 81.98 & 51.73 & 54.68 \\
Median & 47.74 & 57.98 & 49.31 & 63.7 & 43.56 & 44.42 \\
Coefficient of variation (CV) & 925.62 & 1821.18 & 960.86 & 1941.14 & 800.56 & 1106.15 \\
Kurtosis & 65.01 & 1188.37 & 60.20 & 925.53 & 62.61 & 27.41 \\
Skewness & 5.69 & 26.89 & 5.55 & 24.65 & 5.33 & 3.65 \\
Gini Coefficient & 33.8 & 37.3 & 34.25 & 36.58 & 32.09 & 35.38 \\
E(0) & 19.67 & 24.12 & 20.16 & 22.98 & 17.51 & 21.43 \\
E(1) & 21.23 & 28.25 & 21.85 & 28.11 & 18.39 & 21.81 \\
E(2) & 31.21 & 64.77 & 32.27 & 67.65 & 25.72 & 28.58 \\
\hline
\end{tabular}

A trend analysis of the distribution of income in the late 1990s shows a persistence of income inequality. Higher levels of income inequalities are recorded at the national levels, but also in urban and rural areas during the recovery phase of the transitional period. Following the slow increase post-1995, which had a declining slope, a more rapid increase in income inequality was recorded in the late 1990s. At the national level, the per capita expenditure-based Gini coefficient, a standard measure of income inequality, increased by about $10 \%$, from 33.87 to $37.35 \%$ between 1997 and 2000 (see Table 1). ${ }^{9}$ The increase is largely driven by rapidly rising wages and salaries, which are more subject to short-term changes, at the higher end of the distribution. This rate of growth remains relatively low, however, compared to the early phase of the transitional period where income inequality was growing at about $40 \%$.

The rise in income inequality in the late 1990s is also illustrated by the dramatic increase in the coefficient of variation, and increased length of the tails relative to the distribution of household per capita expenditure and income here especially captured by the skewness parameter, which measures the symmetry of the distribution. The coefficient of variation increased more than twofold between 1997 and 2000. This rapid increase reflects the high variability at the higher end of the distribution, to the extent that the shift in the measures of central tendency is of a small magnitude (see Table 1). The positive sign of the skewness

\footnotetext{
${ }^{8}$ For instance, consumption provides a better idea on access to a bundle of goods because it can be smoothed by savings, or alternatively, consumption may be viewed as a best proxy for welfare because utility is normally regarded as the benefit from the consumption of goods.

${ }^{9}$ The Gini coefficient is generally defined as follows: $G=\frac{1}{2 n^{2} \mu(y)} \sum_{i=1}^{n} \sum_{i=1}^{n}\left|y_{i}-y_{j}\right|$, where $y_{i}$ is the income of individual $i$ for $i$ taking values between $l$ and $n$, with $n$ the number of individuals in a given distribution. $\mu(y)$ is the arithmetic mean of the distribution. High income inequality is associated with a large Gini coefficient.
} 
coefficient and its magnitude suggest that the empirical distribution is more tailed off to the right. The rise in income inequality, and particularly at the higher end of the distribution is more important in urban areas, where changes in the coefficient of variation, skewness and entropy measures are more significant. This is especially reflected in the magnitude of the Theil index $(E(1))$ and the second entropy measures $(E(2))$.

The urban-rural contrast on the income inequality scale is even more pronounced and systematic from the distribution of income. While the income distribution-based Gini increases by over 5 percentage points in urban areas, a fall of about 4 percentage points is recorded in rural areas (see Table A.1 in Annex). In fact, at about 31 in 2000, the per capita income-based Gini in rural areas is almost equal to the national estimate recorded in the first period, suggesting tapering off of income inequality. Hence, the rapid increase at the national level reflects more the changing scope of income inequality in urban areas.

The increase in income inequality is also consistent across all income groups and deciles, as reflected in the smoothness of the two Lorenz curves (see Figure A.1 in Annex). This figure is based on the distribution of monthly household per capita expenditures in 1997 (the inner curve) and 2000 (the outer curve). The orthogonal distance between the 45 degree line and the outer curve is uniformly higher than the same distance up to the inner curve, confirming the over time increase in income inequality. However, the Gini and associated Lorenz curves capture variance in the middle part of the distribution, which may not fully account for changes at the higher and lower end of the distribution where the bulk of the poor are concentrated. To account for income variance across the entire spectrum of the distribution, we also estimate a number of income inequality measures from the generalized class of entropy $E(\alpha) .{ }^{10}$ These entropy measures specifically capture income variances at the higher and lower ends of the distribution and should complement the Gini coefficient.

The parameter $\alpha$ can be assigned any real value: specifying a high value yields an index that is more sensitive to distributional changes at the higher end of the distribution, while a lower or negative value yields indices attaching larger weights to changes at the lower end of the distribution. Given our focus on the tails of the distribution, two entropy measures are of particular interest: the mean log deviation, which is more sensitive to changes in the lower end of the distribution $E(0)$, and the half of the square of the coefficient of variation $E(2)$, which is more sensitive to changes at the higher end of the distribution. Between these two measures, there is the second entropy measure $(E(1))$, which is also known as the Theil

${ }^{10}$ The generalized entropy family of income inequality measures $E(\alpha)$ is defined by the following representation:
$E(\alpha)=\frac{1}{\left(\alpha^{2}-\alpha\right)}\left[\frac{1}{n} \sum_{i=1}^{n}\left(\frac{y_{i}}{\mu(y)}\right)^{\alpha}-1\right]:$ when $(\alpha=0), E(0)=(1 / n) \sum_{i=1}^{n} \log \left(\mu(y) / y_{i}\right)$ is the mean
$\log$ deviation; when $(\alpha=1), E(1)=(1 / n) \sum_{i=1}^{n}\left(y_{i} / \mu(y)\right) \log \left(y_{i} / \mu(y)\right)$ corresponds to the Theil index;
when $(\alpha=2), E(2)=\frac{1}{2 n \mu(y)^{2}} \sum_{i=1}^{n}\left[y_{i}-\mu(y)\right]^{2}$ is half of the square of the coefficient of variation. This last measure will be particularly relevant in assessing the changes at the higher end of the distribution. For further details, see Osberg [1991], Canagarajah, Mazumdar and Ye [1998]. 
index. Note that the rapid increase observed in the Gini and coefficient of variation is consistent on the scale of entropy measures. In particular, the more rapid increase in the second and third entropy measures over time further corroborates the impact of changes at the higher end of the distribution, to the extent that the magnitude of changes in income inequality on the entropy scale is proportional to $\alpha$, and the largest increase is recorded for $(\alpha=2)$. $^{11}$

In a context where wages and salary are the main sources of income, and where unemployment continues to be limited, the increased income inequality may also be partly driven by the widening income gaps between poor and non poor, reflecting the rising return to higher education. Between 1997 and 2000, the income share of the upper $20 \%$ of the distribution increased from $41.7 \%$ to about $45 \%$, partly at the expenses of the poorest 20 percent of the population, whose already low income share declined further to $6.5 \%$ during the same period (see Table A. 2 in Annex). Similarly, despite the decline from its peak of almost 21 percent in 1996, unemployment rates continued to be high and by 2000, were estimated to about 14.5 percent (IMF [2003]). Compared to other countries in Eastern Europe and Central Asia, the contribution of salaries and wages to overall income inequality was already high in Latvia, where it accounted for over 60 percent of aggregate income inequality in the late 1990s (World Bank [2000b]). ${ }^{12}$ The widening wage and income differentials between poor and non poor are likely to further increase the contribution of wage to income inequality.

The potential wage effect is also corroborated by a much faster increase in income inequality in the Riga region, where most income is in the form of wages and salaries. At 37, the Gini coefficient in the Riga region is close to the national estimate and substantially higher than the estimates recorded in most other regions (see Table A. 3 in Annex). The changing pattern of income inequality across geographic regions in the late 1990s contrasts with the early phase of the transition where no significant difference in income inequality was recorded across regions. Indeed, in the last Poverty Assessment, the Gini coefficient was about 33 across all five main geographical regions (World Bank [2000a]).

In addition to the prospects of a rising income gap between the poor and non-poor over time, and wage dispersion, there may be other possible causes of rapid increase in income inequality in Latvia. The first set may be associated with the growth prospects and constraints imposed by the transition to market economy. In particular, these include rising returns to education, increased risk-rewards in the post-socialism period (primarily characterized by fostering of risk-taking behaviors), and more importantly the limited prospects to the poor for hedging against risks and uncertainty, partly inherent to their limited share of assets endowments. Returns to higher education increased significantly during most of the transition

${ }^{11}$ In this particular case: $\frac{\Delta E_{t}(0)}{E_{t}(0)}<\frac{\Delta E_{t}(1)}{E_{t}(1)}<\frac{\Delta E_{t}(2)}{E_{t}(2)}$, where, $\frac{\Delta E_{t}(0)}{E_{t}(0)}=22.7 \%, \frac{\Delta E_{t}(1)}{E_{t}(1)}=33.1 \%$, and $\frac{\Delta E_{t}(2)}{E_{t}(2)}=107.3 \%$.

${ }^{12}$ Latvia ranked third; Hungary and Estonia were the only two countries in the sample with higher contribution of salaries and wages to overall income inequality. Other key components of income inequality in Latvia include selfemployment and state transfers, which account for over $22 \%$ and $5 \%$ of total income inequality, respectively. 
period. The percentage contribution to total inequality explained by differences between education groups was estimated at about 10 in the late 1990s.

There are other factors, which may be viewed as consequences of the numerous economic downturns recorded in most of the transitional period, including the collapse of formal wages, accumulation of arrears and reduction of income generating opportunities. The successive economic downturns are believed to have led to a rapid increase of selfemployment and large scale movement toward subsistence agriculture in most transition economies (World Bank [2000b]). In the Latvian case, it is estimated that self-employment contributed to about $22 \%$ to overall income inequality in the late 1990 s, despite its relatively small size. Indeed, compared to other transition economies, self-employment is less common in Latvia, and has been declining steadily, representing less than $10 \%$ in 2002, the lowest among Central European countries (Republic of Latvia [2003]). In fact, the data on the labor market and demographic structure suggests continued increase of pensioner households, which in the late 1990 s represented about $32 \%$ of the total. To the extent that pensioner households have a relatively stable flow of resources over their income stream, this could further fuel income disparities and widening income gaps between poor and non poor, especially in a context of increasing returns to education, rewards for risk-taking behaviors and rising wages at the higher end of the distribution.

In order to prevent further deterioration of living standards, and reduce income disparities between non poor and poor, Latvian authorities have designed a transfers scheme to provide direct assistance to the latter group. These include social security transfers, local transfers and unemployment benefits and compensation. The magnitude of social transfers increased significantly during the transitional period, reflecting the government focus on poverty alleviation. The increase in social transfers is illustrated by continued rising trends in social expenditure. For instance, expressed as a percentage of GDP, social expenditures increased from 12.5 to over 19\% between 1992 and 1999 (OCDE [2003]).

Though the targeting of these transfers has not always been effective and efficient given the scope of leakages, they are believed to be inequality-reducing (Milanovic [1999], World Bank [2000a]). ${ }^{13}$ Hypothetically, in the absence of state social transfers in the form of social security, the household per capita income-based Gini coefficient would be higher (about 39, instead of 34) in 2000. Similarly, in the absence of unemployment compensation and benefits, the Gini coefficient would be over 36.2. ${ }^{14}$ Local transfers are also inequalityreducing, in spite of their relatively small size. In the absence of such transfers to households (particularly local and municipal transfers), the Gini coefficient in 2000 would be about 36. While the transfers have been inequality-reducing, they have not been particularly effective in helping those at the bottom of the income distribution move out of poverty, probably reflecting the bias in income distribution and leakages. In the 2000 household survey, social transfers to households represented about 28 percent of aggregate household income, and most of it was directed to urban households.

\footnotetext{
${ }^{13}$ This is consistent with the "transfer axiom", and to the extent that inequality-reducing transfers among the poor should be poverty-reducing, one should expect the impact of social transfers to extend beyond the scope of income inequality and contribute to the improvement of welfare and living standards.

${ }^{14}$ Indeed, at about $24 \%$ of household disposable income, public transfers in the form of pensions is relatively high in Latvia, higher than the EU average of $17 \%$. By contrast, transfers in the form of unemployment benefits is low, less than $0.7 \%$ of household disposable income, significantly below the EU average of $2.4 \%$ (Heady, Mitrakos and Tsakloglou [2001]).
} 
Despite the rise in income disparities in the late 1990s, income inequality in the Republic of Latvia continues to fall within the range observed in most transition economies, probably as a result of existing redistribution and social transfer mechanisms. In fact, Latvia remains at the lower end of the range when compared to countries such as the Russia Federation, Moldavia, and most countries from the Caucasus and Central Asia region, which have Gini coefficients exceeding 40\% (World Bank [2000b]). ${ }^{15}$ The levels of income inequality in these other transition economies are comparable to the ones observed in a number of countries in Latin America where the pervasive asset and income inequality has been singled out as the most direct proximate causes of persistence in poverty (Londono and Székely [2000]). Moreover, most recent empirical evidence seems to suggest that the declining rate of growth in income inequality observed during the recovery phase of the transition has continued. This could be accelerated by the government's decision to increase the minimum wage to reduce the income gaps between poor and non poor.

However, in the short- to medium-term, the continued rise in income inequality, albeit of smaller magnitude, is likely to negatively impact the prospects for poverty reduction in the recovery phase of the transitional period. There is ample empirical evidence suggesting that income inequality is negative for poverty reduction, even in countries experiencing high income growth, since the rate of decline in poverty tends to be slower than that observed in countries experiencing a more equitable growth. Assessing the relationship between income inequality, growth and poverty reduction, Martin Ravallion [2001] found that the median rate of decline in the proportion of the population living below US\$1/day among countries with both rising average income and rising inequality was about $1.3 \%$ per year, significantly lower than the poverty reduction rates that would be in effect in a more equitable growth scenario characterized by increased average living standards and falling income inequality. Indeed, by contrast to the latter, the more equitable growth scenario produced a median rate of poverty reduction seven times higher (about $10 \%$ per year). ${ }^{16}$

Similarly, a study assessing the welfare effects of income inequality at the regional level, and contrasting Latin American and Eastern European countries found that significantly lower poverty rates would be recorded in Latin American countries (LAC), with the proportion of population below the poverty line falling to less than 3 from 35 percent if the LAC region was growing at the same rate, but with the distribution of income mirrored by that observed in Transition Economies or East Asia (Londono and Szekely [2000]). This result clearly illustrates the contrast between countries in Transition Economies and countries in the LAC region on the income inequality scale. It highlights the potential welfare implications of highly unequal distribution of income. The study also reveals a strong correlation between income inequality and worsening poverty, with headcount above 40 percent in countries with Gini exceeding 57. ${ }^{17}$

\footnotetext{
${ }^{15}$ High income inequality among these countries include Armenia, Turkmenistan, Tajikistan, Kyrgyz Republic and Georgia.

${ }^{16}$ For further details, see Ravallion [2001].

${ }^{17}$ The four countries with the largest Gini coefficients also recorded the largest headcount index. These countries include Brazil, Guatemala, Honduras and Panama. Brazil which has the largest Gini (61.4) had a headcount index of $44 \%$; Honduras which has a Gini coefficient of 57 recorded the largest poverty rate of $65.6 \%$ (Londono and Szekely [2000]).
} 
Of course rising income inequality is even worse for contracting economies, and empirical evidence has also shown that poverty rates can increase by up to $14 \%$ per year in countries experiencing concurrently falling income growth and rising income inequality. In a recent study published by the World Bank, "Making Transition Work for Everyone", the results of a simulation suggest that poverty could be reduced by more than $50 \%$ in Transition Economies over a 10 -year period if the region were to grow at 3.7 percent per year and if growth were shared evenly among the population. The same study suggests that poverty might actually increase among transition economies, if income inequality were to worsen by more than 20 percent and aggregate growth were much lower (World Bank [2000b]).

A simulation of the poverty impact of income inequality under constant growth rates in Latvia further corroborates these results. ${ }^{18}$ Under the more unequal distribution of income of the late $1990 \mathrm{~s}$, the poverty elasticity with respect to the Gini coefficient is $3.65 \%$, implying that a $1 \%$ increase in mean consumption would yield almost a $3.7 \%$ reduction in poverty. Although, higher than poverty-income elasticity observed in countries with highly unequal income distribution, this elasticity is lower than the one which would have been obtained under the hypothetical assumption of constant growth rates, with the distribution of income mirrored by that of 1997, which has a lower Gini coefficient. Under that least unequal distributional assumption, the elasticity would be about $4.25 \%$, implying that a $1 \%$ increase in mean consumption would yield almost a $4.25 \%$ reduction in poverty, ceteris paribus. This represents an income-inequality driven poverty-reduction deficit of over .6 percentage points.

\section{Dynamics of Poverty and Correlates of Welfare in the late 1990s}

In the absence of an official poverty line, the last World Bank Poverty Assessment used a threshold of $28 \mathrm{LVL}$ per person per month for welfare inference. At the time, that line represented about $50 \%$ of the officially accepted minimum crisis basket (MCB), a line then considered too high by the authorities. In fact, during that period, the notional poverty line defined in the 1995 Welfare Law and recommended by the Ministry of Welfare was 2 LVL lower (World Bank [2000a]). Since the last Poverty Assessment, a number of steps have been made toward the establishment of an institutional threshold for welfare inference. Latvian authorities increased the minimum wage to 70 LVL early in 2003 (OECD [2003], IMF [2003]). ${ }^{19}$ However, these social reforms have not yet gone as far as defining an official absolute poverty line. Short of such a line, and to allow over time comparisons, we use an update of the last poverty line for welfare inference, following adjustment for inflation over time. In terms of $2000 \mathrm{LVL}$, the poverty line is established at $30 \mathrm{LVL}$ per person per month, representing about $7 \%$ increase and $43 \%$ of the revised minimum wage. ${ }^{20}$

For sensitivity analysis, the last Poverty Assessment used different poverty lines, depending on the scope of economies of scale parameter $\theta$. The base line scenario assumes absence of economies of scale $(\theta=1)$. The medium line set at $34 \mathrm{LVL}$ was derived under the

\footnotetext{
${ }^{18}$ The simulation draws on the methodology developed by Kakwani [1993].

${ }^{19}$ More recently, in May 2003, the Government of Latvia approved a document, which envisages a gradual increase of a minimum wage from 70 to 139 LVL per month by 2010, with the latter amount set to represent about 50 percent of the average gross wage of the previous year.

${ }^{20}$ Note that inflation as measured by the consumer price index was much lower in the Euro zone, Latvia's main trading partner, in the late 1990s. Using a PPP adjusted poverty line, which accounts for the weights of traded goods in the household consumption basket would have produced an even lower poverty line.
} 
assumption of a constant ratio between the median monthly household per capita expenditure and the base poverty line. In this particular case, the ratio between the median per capita income and the adjusted poverty line is about 1.95, owing to rapid increase in income in the recovery phase of the transitional period. ${ }^{21}$ Assuming moderate economies of scale $(\theta=.8)$, household per capita median expenditure is about $66.6 \mathrm{LVL}$, and the corresponding poverty line is therefore about $35 \mathrm{LVL}$. This represents about a 3 percent increase, and 50 percent of the revised minimum wage.

The use of economies of scale in poverty analysis in Latvia was first introduced by Gassmann [1998]. Using different values of $\theta$, the author concluded that the ranking of households on the basis of their welfare was relatively stable to changing economies of scale. A variation of that approach was used to assess the potential impact of economies of scale under three scenarios: absence of economies of scale $(\theta=1)$, moderate economies of scale $(\theta=.8)$, and significant economies of scale $(\theta=.6)$, (World Bank [2000a]). Similarly, the last Poverty Assessment concluded that allowing for economies of scale had no significant impact on the poverty mapping. Indeed, despite the urban-rural bias in the poverty gap, which is one of the characteristic features of many low-income and developing countries, the demographic structure and household size in urban and rural areas are not markedly different in Latvia. ${ }^{22}$ As a result, the sensitivity analysis undertaken in the context of this study emphasizes the welfare effects of changing poverty lines. The potential effects of economies of scale are restricted to the moderate economies of scale assumption, which is tested against the base case.

Despite the surge in and persistence of income inequality, the time profile of poverty shows a slight improvement of welfare and living standards in Latvia between 1997 and 2000, owing to an exceptionally large increase in per capita income, especially urban income. The positive shift in the median of the distribution of monthly per capita household expenditure is more than mirrored by the mean per capita household expenditure (see Table 1). The latter is more sensitive to extreme values, and increased even more rapidly, from about 58 LVL to over 74 LVL, representing about a 28 percent increase. With an increase in household income of that magnitude, the incidence of poverty fell by over 27 percent at the national level, from about $19.4 \%$ to less than 14 percent (see Table 2 ). ${ }^{23}$ The table provides estimates of the headcount, the poverty gap and severity indices over the two reference periods, and across all geographic

\footnotetext{
${ }^{21}$ Between 1997 and 2000, the median household per capita expenditure increased by about 23\%, from 47 to 58 LVL.

${ }^{22}$ In fact urban areas account for about $70 \%$ of the total population. Unlike most developing countries, urban and rural household size and structure are not markedly different: between 1997 and 2000, the average household size was relatively stable, around 2.33 in urban areas and 2.50 in rural areas. In Sub-Saharan African countries, average household sizes are larger, and urban-rural differences are more important. In the Gambia for instance, the average household size was about 8.9 at the national level, 11.4 in rural areas and 7.1 in urban areas. At the same time significant differences existed across expenditure quintiles, with the lowest quintile having an average household size of 14, and the uppermost quintile having an average of 7 (World Bank [1998]).

${ }^{23}$ Naturally, using a higher poverty line will lead to slower decline in poverty; for instance, assuming a $20 \%$ increase in the median income in a recent study carried out by the Central Statistics Bureau lead to a slower decline in poverty.
} 
regions. ${ }^{24}$ These indicators are derived under the assumption of no economies of scale $(\theta=1)$ using the base poverty line.

The benefits of growth were not equally distributed across geographical regions and the different income groups. The rise in household income was more rapid in urban areas, where the monthly average per capita expenditure reached $82 \mathrm{LVL}$, representing a $35 \%$ increase.

Similarly, a more rapid decline in poverty and improvement in living standards was recorded in urban areas where the incidence of poverty, already low, fell to an even lower level $(9.2 \%$, from $15.6 \%$ in 1997, representing more than $41 \%$ decline). The largest improvement in welfare was recorded in Riga, where the incidence of poverty fell to $6.7 \%$, reaching an all time low level. A large reduction in poverty was also recorded in other cities where the headcount fell from 19 to $12 \%$, reflecting a concurrent rise in income. However, the decline in poverty was less rapid in rural areas where household income grew at a slower rate, hence widening the urban-rural income and poverty gaps. The incidence of poverty remains relatively high, at about $26 \%$, barely representing a $9 \%$ decline from $1997 .^{25}$ The decline in the poverty gap, an indicator of vulnerability, was even lower, suggesting that a large fraction of poor households continues to have per capita income falling significantly below the poverty line.

Table 2: Poverty by Geographical Regions under the Assumption of no Economies of Scale $(\theta=1)$

\begin{tabular}{|c|c|c|c|c|c|c|}
\hline \multirow[b]{2}{*}{ Economic Regions } & \multicolumn{3}{|c|}{$\begin{array}{l}\text { Household Budget } \\
\text { Survey } 1997(\theta=1)\end{array}$} & \multicolumn{3}{|c|}{$\begin{array}{l}\text { Household Budget } \\
\text { Survey } 2000(\theta=1)\end{array}$} \\
\hline & P0 & P1 & P2 & P0 & P1 & $\mathbf{P 2}$ \\
\hline Riga & 12.6 & 3.5 & 1.5 & 6.76 & 1.93 & 0.82 \\
\hline Kurzeme & 24.5 & 8.0 & 3.8 & 16.61 & 4.50 & 1.79 \\
\hline Vidzeme & 24.1 & 6.9 & 2.9 & 23.31 & 7.14 & 3.41 \\
\hline Zemgale & 20.6 & 5.2 & 2.0 & 15.14 & 4.36 & 1.85 \\
\hline Latgale & 30.0 & 8.4 & 3.6 & 24.17 & 7.24 & 3.11 \\
\hline Rural Areas & 28.5 & 8.3 & 3.6 & 25.86 & 7.93 & 3.56 \\
\hline Urban Areas & 15.56 & 4.39 & 1.87 & 9.15 & 2.51 & 1.03 \\
\hline Other Urban & 19.5 & 5.3 & 2.2 & 12.05 & 3.22 & 1.26 \\
\hline Latvia & 19.4 & 5.5 & 2.4 & 13.99 & 4.09 & 1.76 \\
\hline
\end{tabular}

The widening urban-rural poverty and income gap over time is illustrated by the poverty incidence curves depicted in Figure 1. This figure compares the poverty incidence curve in

\footnotetext{
${ }^{24}$ These measures generally known as Foster-Greer and Thorbecke can be estimated using the following formula: $P_{\alpha}=\frac{1}{n} \sum_{i=1}^{q}\left[\frac{\left(z-y_{i}\right)}{z}\right]^{\alpha}$, where $\alpha=0,1,2$; and $q$ is the number of poor individuals; $z$ is the poverty line, and $y_{i}$ is the consumption of the $i t h$ individual below the poverty line.

${ }^{25}$ The urban-rural contrast in the poverty rates and welfare gaps is pervasive in most Eastern European and Former Soviet Union countries, including the great reformers. In Bulgaria and Poland for instance, rural poverty rates are almost twice the urban rates (Braithwaite, Grootaert and Milanovic [2000]).
} 
urban and rural areas. On the $x$-axis, we have the monthly per capita household expenditure plotted against the cumulative distribution of population on the $y$-axis. This figure provides a good illustration of first-order dominance. The cumulative frequency distribution of the population corresponding to the poverty incidence curve for rural households is uniformly above the cumulative frequency distribution of urban households for the period 2000 and the gap between the two curves is significant, suggesting that poverty is uniformly higher in rural areas (Ravallion [1992]).

Figure 1: Poverty Incidence Curves for Distributions of Urban and Rural Per Capita Household Expenditure in LVL (2000)

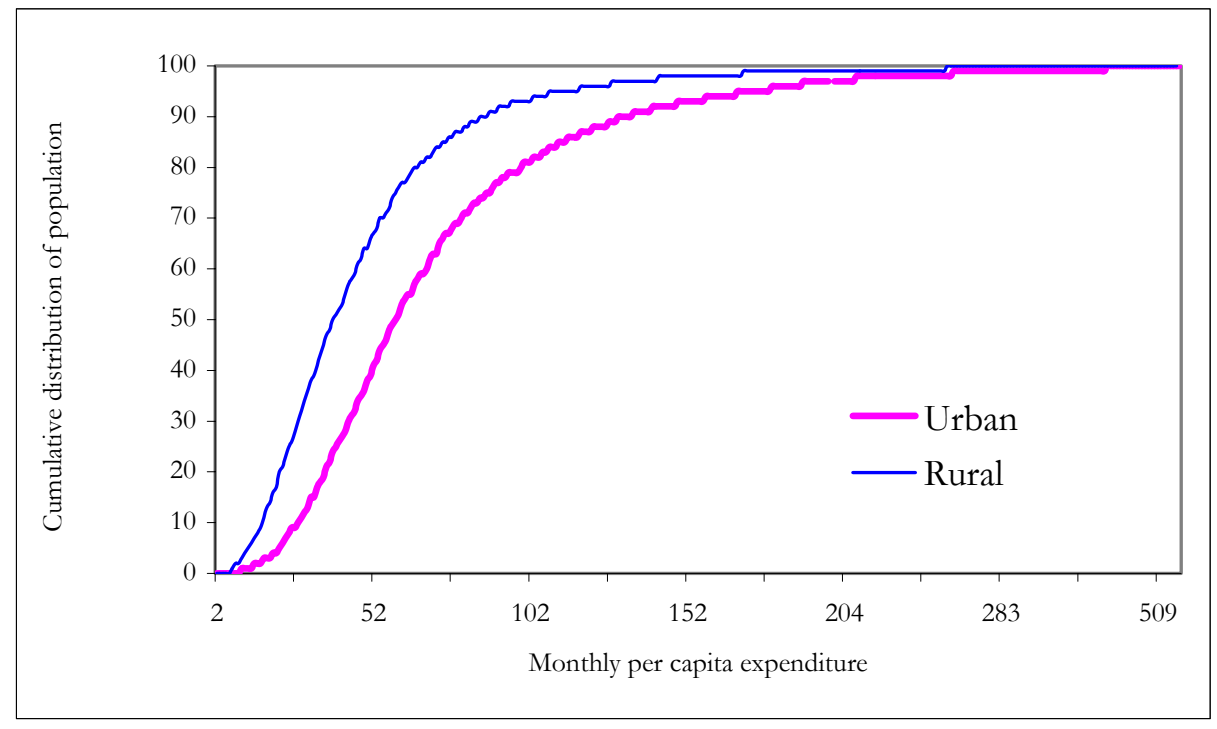

Source: Latvia Household Budget Survey (HBS 2000).

We also construct poverty incidence curves to assess the dynamics of welfare in urban areas (see Figure 2) and rural areas (see Figure 3). Similar to Figure 1, the cumulative distribution of the population appears on the $y$-axis and monthly per capita household expenditures on the $x$-axis. Note that for Figure 2, the poverty incidence curve corresponding to 1997 is uniformly above the curve corresponding to the year 2000. Moreover the gap between the two curves is significant over the support of the monthly household per capita expenditure range, suggesting that poverty is systematically lower in the latter year. However, a comparison of rural poverty incidence curves over time produced ambiguous results. Below the poverty line, the two curves intersect more than once. This reflects the relatively low improvement of living conditions in rural areas, and suggests that a number of poor households may have witnessed a deterioration of their welfare in the late 1990s, in spite of the general improvement during the recovery phase of the transition. By contrast, the rural poverty incidence curve for the latter year is everywhere dominated by that of the earlier reference period for $z>32$, suggesting a larger increase in income at the higher end of the distribution in the latter year.

Surprisingly, in spite of the widening urban-rural income gaps - which may be a reflection of labor market segmentation where rural workers earn substantially less than urban counterparts for the same level of education and years of experience, the urban-rural poverty gap is not reflected in the outcome of the perception survey, which provides qualitative self- 
assessment of the evolving trend in poverty. ${ }^{26}$ Assessing the level of improvement of welfare in the late $1990 \mathrm{~s}$, about $47 \%$ of the urban population indicated a consistent deterioration of their living conditions. The figures were lower in rural areas, where only $37 \%$ of the population indicated that their living standards have somehow deteriorated. The poor- non poor breakout provides a more consistent outcome at the national and regional level, though the figures remain much lower in rural areas. At the national level, $41 \%$ of non poor indicated a deterioration of their living conditions, against about $65 \%$ for the poor who provided concordant information on the state of their welfare. The highly negative perception expressed by the urban poor is preserved along geographical boundaries. About $80 \%$ of urban poor indicated a further deterioration of their living conditions, against only $53 \%$ of rural poor who expressed the same level of non satisfaction.

The regional profile of poverty shows an overall improvement of welfare in the late 1990s. The improvement is consistent across all the regions, including Latgale, the poorest region of Latvia. However, the urban-rural gaps in the growth of household income affected the changing regional profile of poverty. The largest gain in the recovery phase of the transitional period is achieved in the Riga region, where the headcount index fell by about $50 \%$, reflecting the continuous rise in urban household income observed in the 1996-1999 period (Republic of Latvia [2003]). For instance, the monthly per capita income increased by about 40\% between 1996 and 1999 in Riga and the latest surge in 2000 is consistent with ongoing patterns.

The significant improvement in welfare in urban areas, and particularly in the Riga region may reflect the fact that the relatively high and sustainable growth rates recorded in the aftermath of successive economic downturns were largely skewed, with an urban bias. The apparent skewness is highlighted by the distribution of unemployment and wages across geographical regions. The average gross wage differs significantly between Riga and other regions, and is over $40 \%$ higher than in Latgale, the poorest region of Latvia. Similar gaps in the wages are observed between Riga and most other regions (Republic of Latvia [2001]). Hence, residing in the Riga region comes with a substantially high wage premium. The overall improvement in the Riga region is also illustrated by the relatively low unemployment rate there. While long-term unemployment is over 7\% in Latgale, significantly lower rates are recorded in Riga (less than 1\%). Similarly, while registered unemployment is over $18 \%$ in Latgale, it is less than 5\% in Riga.

By contrast, the aggregate per capita income increased by less than 7 percent in rural areas during the same period (1996-1999). This weak income growth in rural areas partly contributed to the slower declining rates of poverty in the other 4 regions of Latvia (see Table 2). Particularly affected is the region of Vidzeme, where the poverty incidence remains constant at about $24 \%$ over the two reference periods. Worse, the poverty gap $\left(P_{1}\right)$ even increased, suggesting higher vulnerability. As a result of increased vulnerability, the total amount of resources required to eradicate poverty under perfect targeting and in the absence

\footnotetext{
${ }^{26}$ In fact the labor market segmentation goes beyond spatial dimension: though there is a significant wage premium associated with working in urban areas, labor market segmentation also has a gender dimension. Already in the mid1990 s, earnings in urban areas were $27 \%$ higher for men and $15 \%$ higher for women. At the same time, men and women in Latgale, the poorest region, received earnings 27\% less than in Kurzeme (World Bank [2000a]). This bias persisted in the late 1990s and up to 2002: Indeed, employees working in a rural area earned 10\% less than an otherwise similar employee in a small city in 2002; and similarly, employees working in Riga earned $37 \%$ more than those working in smaller towns (OECD [2003]).
} 
of incentive effects in transferring money would be much higher in Vidzeme, notwithstanding the marginal decline in the poverty incidence. ${ }^{27}$ In addition to Riga, Kurzeme is the other region that benefited the most from the growth process, with over $32 \%$ decline in poverty incidence and about a $50 \%$ fall in the poverty gap.

Figure 2: Over Time Poverty Incidence Curves for Distributions of Urban Per Capita Household Expenditure in LVL (1997 - 2000)

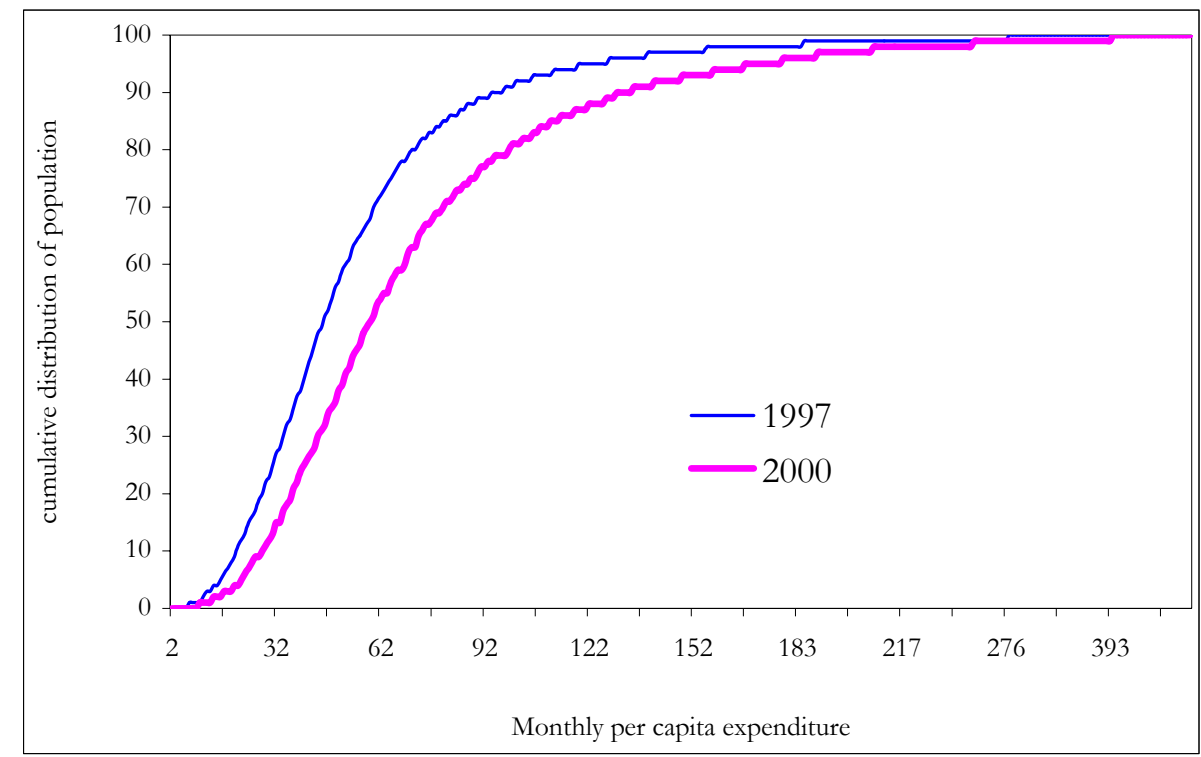

Source: Latvia Household Budget Surveys (HBS 1997, 2000).

Figure 3: Over time Poverty Incidence Curves of Rural Per Capita Household Expenditure in LVL (1997 - 2000)

\footnotetext{
${ }^{27}$ Under the assumption of perfect targeting, the total amount required to eradicate poverty is a function of the poverty gap, the poverty line and the total population and can be expressed as $y=n z p_{1}$. For instance, in this particular case, where the region of Vidzeme accounts for about $12 \%$ of total population, the amount of resources required to eradicate poverty over a month period under the best and optimal allocation scenario would be about 617,000 LVL.
} 


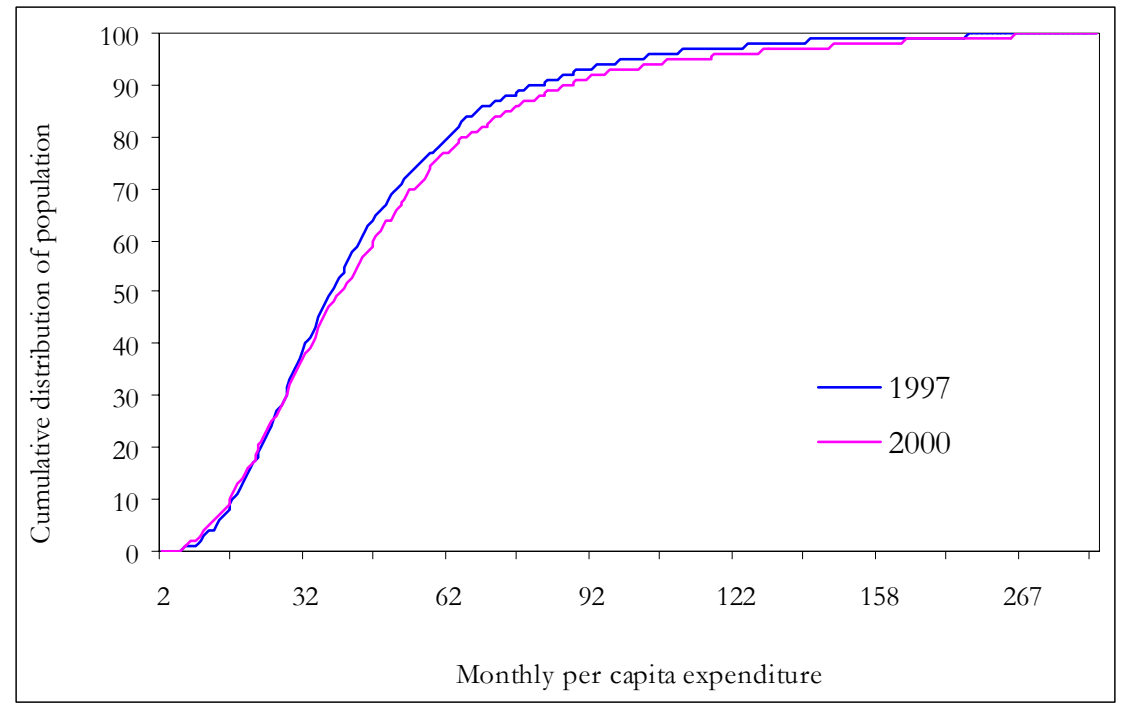

Source: Latvia Household Budget Surveys (HBS 1997, 2000).

This exceptional improvement in welfare in the region of Kurzeme has implications for the configuration of the Latvian poverty map (see Figure 4, to be contrasted with Figure A. 2 in the Annex, which provides a mapping of poverty in 1997). Figure 4 provides the geographical and socioeconomic mapping of poverty in Latvia in the late 1990s. Vidzeme and Latgale are now the poorest regions of Latvia, despite the slight improvement in the latter, which witnessed a rapid decline in its headcount index, from 30 to about $24 \%$. In spite of the improvement, it continues to exhibit the largest poverty gap, an indication of persistence of the high vulnerability of its population and its relatively low income. The region of Latgale has the lowest wage rate and the highest unemployment rates, which may partly explain the continued high vulnerability of its population.

Unemployment is indeed a key determinant of poverty in Latvia, with implications for the regional distribution of welfare. Latgale, the most poverty-stricken region, has the highest rate of jobseekers (over 22\%), the highest rate of registered unemployment (over 15\%), and long-term unemployment (over 7\%) (Republic of Latvia [2003]). Moreover, the contrast between wage and non wage income on the poverty mapping scale is significant across all geographical regions. This contrast is illustrated by Figure 5, which provides the mapping of poverty incidence across regions for the wage income earners and self-employed workers, and Figure 6, which provides the same mapping of poverty for households living on social transfers. For the poverty-stricken region of Latgale, the poverty incidence gaps between wage income earner households and households deriving their income from direct transfers in the form of social security and unemployment benefits is about $33 \%$. This gap is about $23 \%$ in Vidzeme and much lower in all the other regions.

The updated geographical mapping of poverty is actually stable with respect to differing assumptions on economies of scale. Latgale and Vidzeme remain the two poorest regions under moderate economies of scale assumptions (see Table 3). This result is consistent with the last World Bank's Poverty Assessment (World Bank [2000a]). Despite this relative stability, it is worth pointing out the slight increase in the incidence of poverty and the poverty gap in the region of Vidzeme. Also, note that under moderate economies of scale 
assumption $(\theta=.8)$, that region has the largest poverty gap. The stability under economies of scale assumptions is also consistent across socioeconomic groups (see Table A.5 in Annex).

The general improvement in welfare at the national level is reflected in the socioeconomic profile of poverty in the late 1990s. The Wage Earners and Self-employed workers who account for about $61 \%$ of total population and who predominantly reside in urban areas realized the largest gains (see Table 4). The headcount index decreased by about $30 \%$ in the Wage Earners and $42 \%$ among the Self-Employed, respectively. These two socioeconomic groups were already among the least poverty stricken. The exceptional rise of their income will further widen the poverty gaps with other income groups (Gassmann [1998], World Bank [2000a]). The decline in poverty incidence was indeed less rapid in other socioeconomic groups, and especially the "Other Social Benefits", which continues to have the largest poverty incidence (over $40 \%$ at the national level and more than $67 \%$ in rural areas). This suggest that most of the gains accruing to this socioeconomic group primarily benefited the urban population. This is actually reflected in the extremely large urban-rural poverty gaps. The urban poverty incidence for this socioeconomic group is about $23 \%$ in the latter year, suggesting an urban-rural poverty gaps of about $45 \%$.

Figure 4: Mapping of Poverty Incidence by Geographical Region

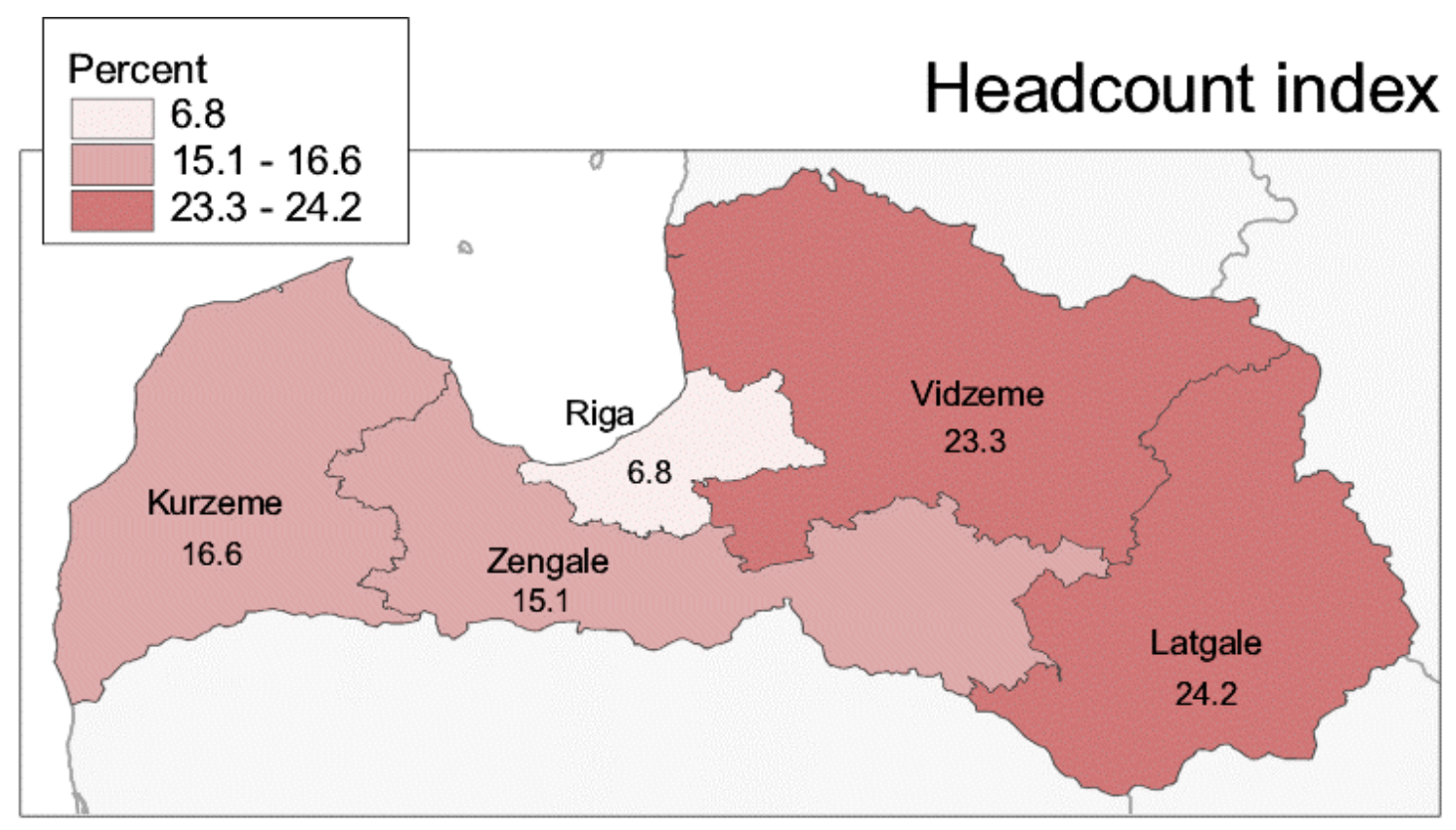

Source: Household Budget Survey (HBS 2000).

Figure 5: Poverty Incidence by Regions for Employed Household Heads (HBS 2000) 


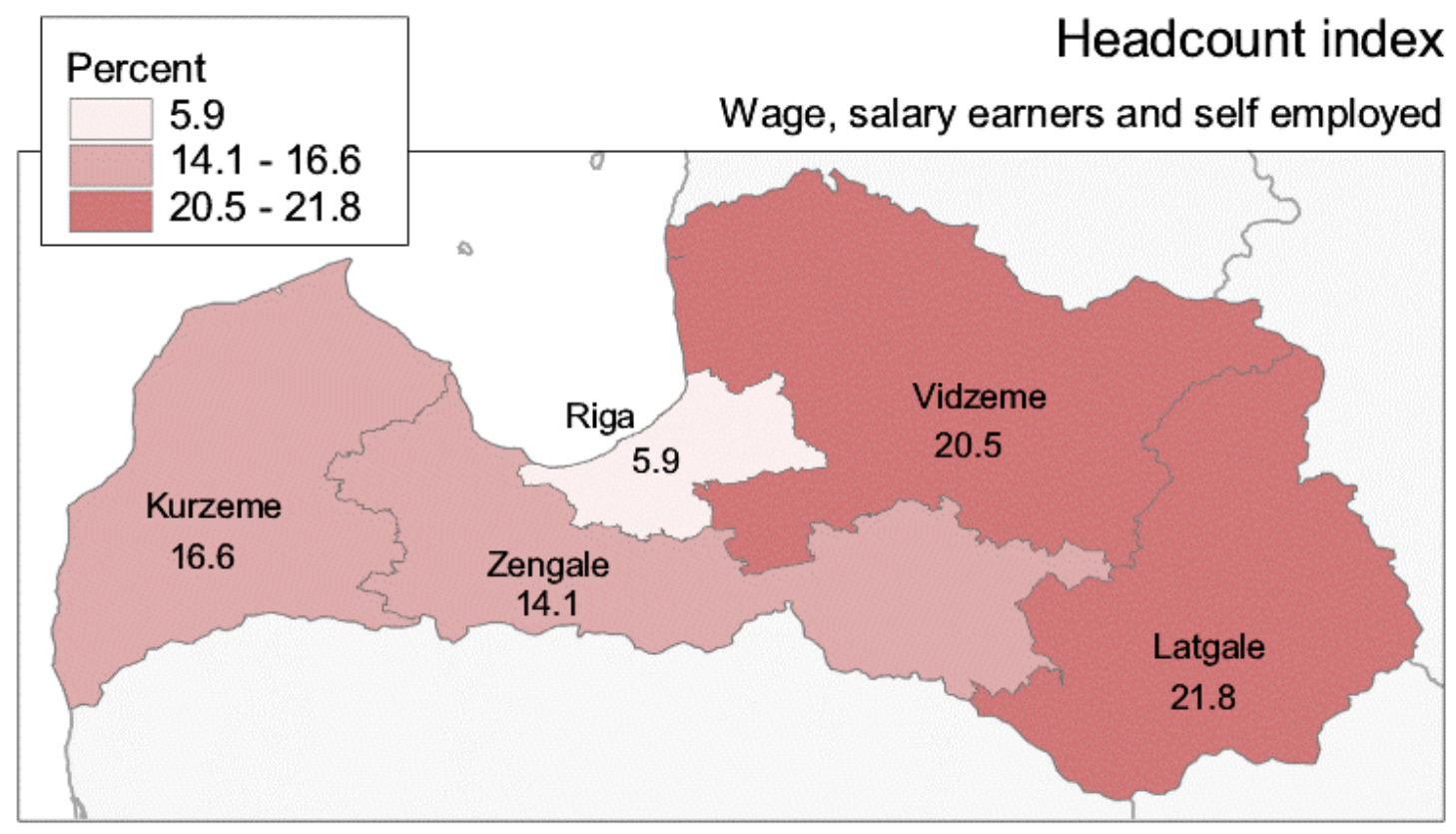

Source: Household Budget Survey 2000.

In addition significant differences exist across geographical regions for this poorest SEG relying on other "social benefits" for income. For instance, while the poverty incidence is less than 10 percent for this income group in the capital region of Riga, it exceeds 54 percent in Latgale, the region with a disproportionately large number of poor relying on social transfers (see Figure 6). This suggests a poverty incidence gaps of about 45 percentage points between these two regions. By contrast, the geographical differences are less significant on the poverty incidence scale when the sample is restricted to households deriving their income from pensions. While the region of Riga continues to have the lowest poverty incidence of about 7.5 percent, Vidzeme, the poverty-stricken region for this income group has the largest poverty incidence of about 22 percent, suggesting a poverty incidence gaps of about 15 percentage points between the two regions (see Figure 7).

Table 3: Poverty by Geographical Regions under the Assumption of Moderate Economies of Scale $(\theta=.8)$

\begin{tabular}{|c|c|c|c|c|c|c|}
\hline \multirow[b]{2}{*}{ Economic Regions } & \multicolumn{3}{|c|}{$\begin{array}{l}\text { Household Budget } \\
\text { Survey } 1997(\theta=.8)\end{array}$} & \multicolumn{3}{|c|}{$\begin{array}{c}\text { Household Budget } \\
\text { Survey } 2000(\theta=.8)\end{array}$} \\
\hline & P0 & P1 & $\mathbf{P 2}$ & P0 & P1 & $\mathbf{P 2}$ \\
\hline Riga & 12.0 & 3.2 & 1.3 & 7.11 & 1.89 & 0.081 \\
\hline Kurzeme & 22.7 & 7.2 & 3.3 & 15.70 & 3.99 & 1.52 \\
\hline Vidzeme & 21.8 & 6.2 & 2.6 & 22.23 & 7.35 & 3.50 \\
\hline Zemgale & 18.0 & 4.3 & 1.6 & 15.45 & 4.17 & 1.68 \\
\hline Latgale & 27.1 & 7.4 & 3.1 & 24.26 & 6.66 & 2.79 \\
\hline Rural Areas & 25.6 & 7.2 & 3.0 & 26.27 & 7.63 & 3.31 \\
\hline Urban Areas (Riga inc.) & 16.41 & 4.55 & 1.93 & 8.91 & 2.36 & 0.09 \\
\hline Other Urban Areas & 17.7 & 4.8 & 2.0 & 11.12 & 2.94 & 1.16 \\
\hline
\end{tabular}




\begin{tabular}{lllllll}
\hline Latvia & 17.8 & 4.9 & 2.0 & 13.95 & 3.89 & 1.65 \\
\hline Authors' calculation. & & & & & &
\end{tabular}

Table 4: Estimates of Headcount Index by Socioeconomic Groups under the Assumption of no Economies of Scale $(\theta=1)$

\begin{tabular}{lllllll}
\hline & \multicolumn{3}{c}{ Household Budget Survey } & \multicolumn{3}{c}{ Household Budget Survey } \\
& \multicolumn{3}{c}{$\mathbf{1 9 9 7}$} & & \multicolumn{3}{c}{$\mathbf{2 0 0 0}$} \\
\hline Socioeconomic Groups & National & Urban & Rural & National & Urban & Rural \\
Wage Earners & 17.1 & 14.01 & 29.7 & 12.29 & 8.24 & 24.51 \\
Self-employed & 16.5 & 12.7 & 18.9 & 9.54 & 7.93 & 22.27 \\
Pension & 19.5 & 13.8 & 25.0 & 13.04 & 7.84 & 23.42 \\
Other Social Benefits & 47.1 & 41.5 & 68.6 & 41.42 & 23.22 & 67.31 \\
Other Income & 29.2 & 25.5 & 34.2 & 22.24 & 19.59 & 28.05 \\
All SEG & $\mathbf{1 9 . 4}$ & $\mathbf{1 5 . 5 6}$ & $\mathbf{2 8 . 5}$ & $\mathbf{1 3 . 9 9}$ & $\mathbf{9 . 1 5}$ & $\mathbf{2 5 . 8 6}$ \\
\hline
\end{tabular}

Authors' calculation.

It is worth pointing out that the size of the poorest socioeconomic group, "Other Social Benefits" is relatively small. While the "Wage Earners " together with the "Self-Employed" account for over $60 \%$ of the active labor force, the poorest socioeconomic group relying on "Other Social Benefits" account for less than $2 \%$ of the total population of Latvia (Republic of Latvia [2003]), and the persistence of widespread poverty among this group may be a reflection of the extreme vulnerability of its population, and mistargeting of social transfers. ${ }^{28}$ This group has the largest poverty gap (16.52), which is highly sensitive to the poverty line. When the poverty line is increased to $35 \mathrm{LVL}$ per person per month, the headcount index rises to 50 percent and the poverty gap to about 21\% (see Table A.4 in Annex). However, the relatively small size of this income group suggests that under perfect targeting, the total amount of resources required to fill its poverty gap would be minimal: less than 212,000 LVL per month and about 2.6 million LVL per year. This represents about $.032 \%$ of GDP, and is relatively small compared to the overall level of social assistance allocated from the budget and municipalities, which accounts for over $20 \%$ of GDP. ${ }^{29}$

The persistence of widespread rural poverty among individuals relying on "Social Benefits", especially in the context of rising social transfers, raises the issues of efficiency of public spending allocation and targeting systems. The issue of efficiency of the targeting mechanism under the existing social transfers scheme was already raised in the last World Bank Poverty Assessment, which found the distribution of social transfers to be almost flat on the scale of income groups, and the amount of leakages extremely high, i.e. in the range of $75 \%$ (World Bank [2000a]). The persistence of widespread poverty in this Socioeconomic group may

\footnotetext{
${ }^{28}$ Some of the key components of social benefits accruing to these poor and vulnerable households include state social insurance benefits such as unemployment benefits, maternity benefits, sick payments, and state social security and assistance benefits such as child care allowances, birth and funeral grants, and local municipalities assistance, housing allowances, cash benefits for improving the health, and cash benefits to low-income families.

${ }^{29}$ In 2003, social transfers (excluding health care) to households was about 1 billion LVL, representing about $12 \%$ of GDP (for further details, see IMF [2003]).
} 
suggest that the benefits expected from the reforms of the social assistance program initiated in the mid-nineties are not yet reflected in the income stream of the poorest segment of this population to impact positively on their welfare.

The persistence of widespread poverty in that socioeconomic group may also be a reflection of a number of characteristics of its population, probably exacerbated by ongoing high unemployment rates. Indeed, the poor in this income group are overwhelmingly unemployed and women. About $65 \%$ of them are unemployed, and an even larger number of households in this income group is headed by a woman (77\%). Surprisingly, the distribution of this particular income group is flat in the scale of age structure and education level of household head. This suggests that education may not be a discriminating factor between poor and non poor, and reflects the significant investment in social infrastructure in the pre-transition period, a positive legacy of the socialism era. In fact, most household heads have attended either primary school or above. ${ }^{30}$

Figure 6: Poverty Incidence by Region for the Poorest SEGs

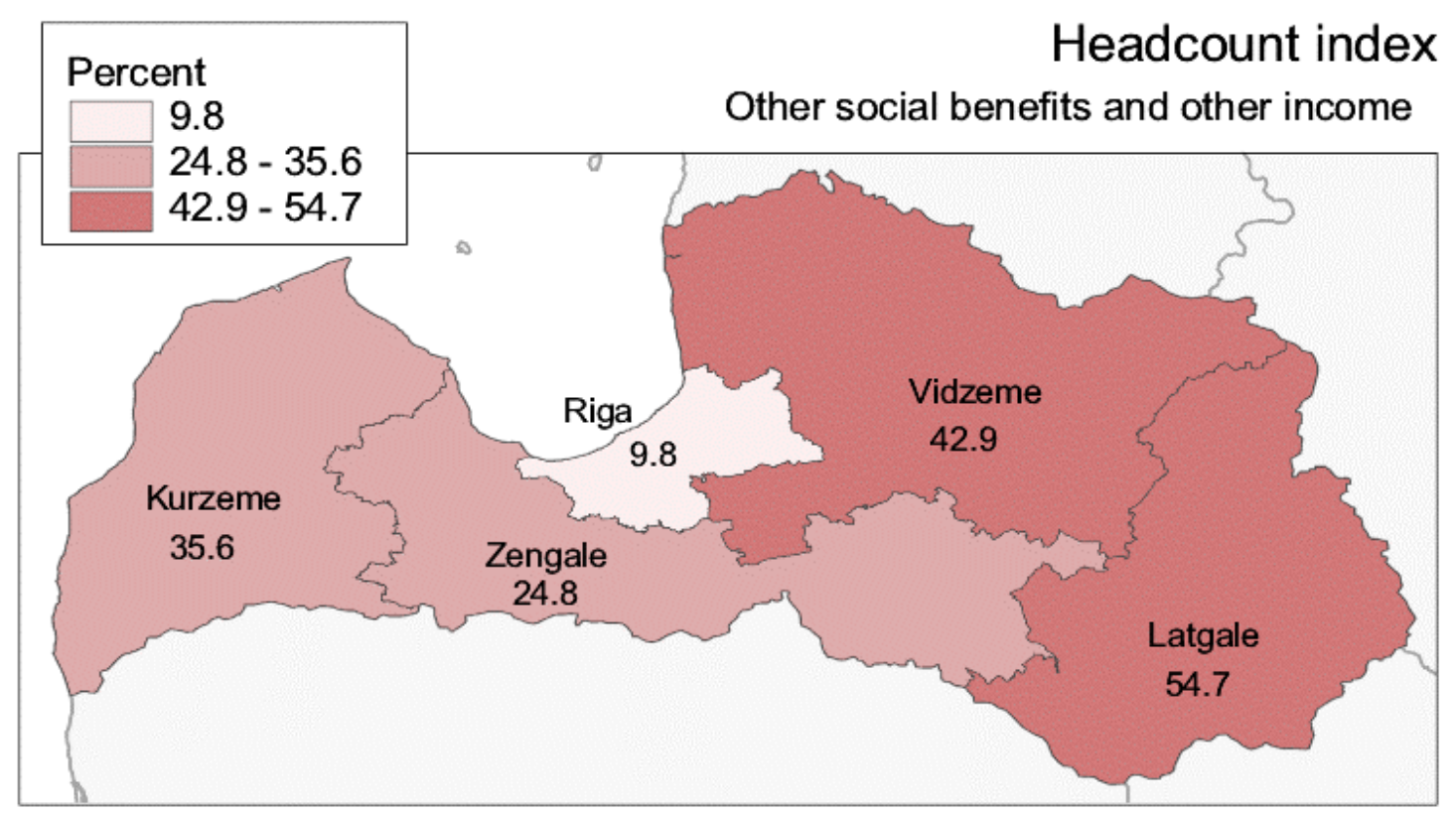

Source: Household Budget Survey (HBS 2000).

Figure 7: Poverty Incidence by Region for SEGs Relying on Pension

\footnotetext{
${ }^{30}$ Though, this is consistent with existing empirical findings, it is at variance with the findings in most developing countries, and particularly Sub-Saharan African countries, where deficits in human capital endowments have been found to be among some of the key characteristics of poor households (Glewwe [1991], Fofack [2002]).
} 


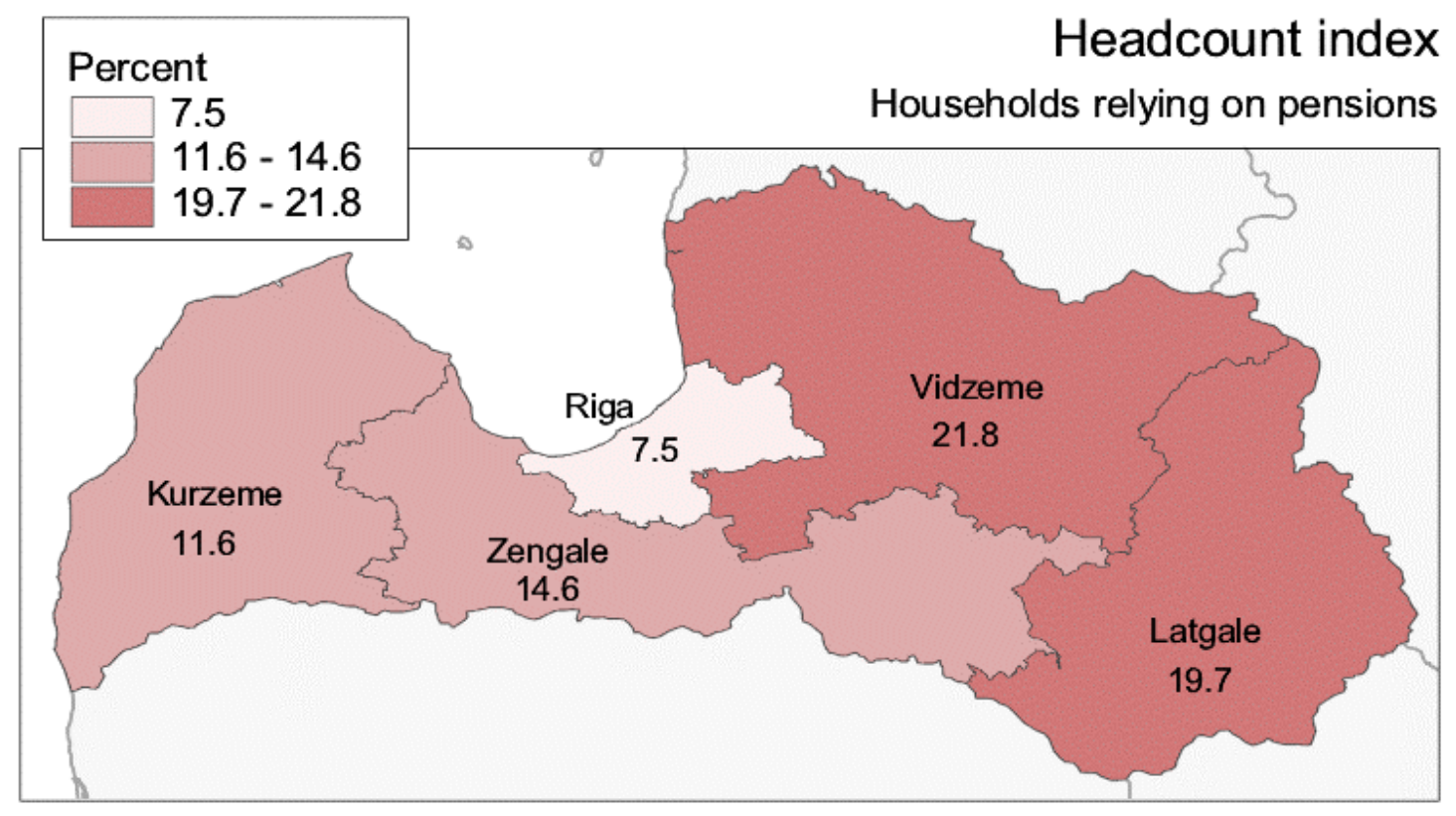

Source: Household Budget Survey (2000).

In a study comparing absolute poverty rates in transition economies between 1995 and 1999 , Latvia's ranking was about average (World Bank [2000b]). On the basis of a US\$2.15/day poverty line based on the 1996 purchasing power parity, the headcount index in Latvia was about $6.6 \%$ in a score of welfare indicators ranging from 0 to about $70 \%{ }^{31}$ However, when that absolute poverty line was increased to US\$4.30/day, Latvia recorded one of the highest increase in poverty. Its headcount poverty increased by more than fourfold, from 6.6 to about $35 \%$, suggesting high vulnerability of a large segment of its population whose per capita income, although above the base poverty line, may fall within its vicinity.

The vulnerability is also illustrated by the sensitivity of the poverty rates to changing levels of the poverty line and/or economies of scale. When the poverty line is increased from 30 to $32 \mathrm{LVL}$, the headcount index increases by over 2 percentage points at the national level and about 4 percentage points in rural areas. The more rapid decline in welfare is recorded in the region of Vidzeme, where the headcount reaches 27 percent (see Table A6 in Annex). Similarly, when the poverty line is increased to $35 \mathrm{LVL}$ under the same assumption of no economies of scale, the headcount index increases to about $20 \%$ at the national level, corresponding to levels recorded in the mid-1990s (see Table A6 in Annex). In rural areas, the increase is even more dramatic, with the incidence reaching the threshold of $35 \%$.

The exceptional rise in income initiated in the early phase of the transition, and sustained throughout the late 1990s, and the following decline in the poverty rate seems to suggest that Latvians are beginning to reap the benefits of a decade-long transition. This outcome is timely, and could pave the way to Latvia's access to EU membership in 2004, especially,

\footnotetext{
${ }^{31}$ The highest poverty rates were recorded in Central Asia and the Caucasus region, particularly in Moldova and Tajikistan, which recorded headcount indices of $55.4 \%$ and $68.3 \%$, respectively. The lowest rates were recorded in Slovenia, Czech Republic where the per capita expenditure on average exceeded the US $\$ 2.15 /$ day poverty line.
} 
given that income-based measures are among the key requirements for accession (Zile and Steinbuka [2001], Republic of Latvia [2003]). Notwithstanding this rapid increase in income and improvement in living conditions, poverty remains exceptionally high in a number of regions, particularly Latgale and Vitzeme where numerous pockets of poverty continue to exist. Achieving broad-based income growth and distribution will be essential to reducing the regional and socioeconomic income gaps and lifting welfare to EU standards. This, however, would require a prior identification of some of the key correlates of poverty, income inequality and growth. It would also require a better understanding of the dynamics of some of these correlates, as well as their relation to poverty and growth over time.

Some of the proximate causes and correlates of poverty in transition economies include output drop, income inequality, and a number of institutional and socioeconomic factors, particularly labor market outcomes such as unemployment rates, low wage rates for unskilled workers, and high dependency ratios at household levels (World Bank [2000b]). Unemployment and wages are likely to be particularly relevant in the Latvian context where over $80 \%$ of households derive their income from either wages and salary or pensions. ${ }^{32}$ In fact, empirical evidence suggests that the presence in a household of one unemployed member could reduce the household welfare by over 25\%; with this percentage decline in welfare increasing to over $40 \%$ if the household head is unemployed (World Bank [2000a]).

Similarly, assessing the correlates of poverty in the late 1990s, we found a significant association between poverty and a number of variables, including unemployment, dependency ratio, and household ownership of real and financial assets. The significance of the association is reflected in the magnitude of the correlation coefficient between poverty, measured by monthly household per capita expenditure, and unemployment ratio. The sign of the correlation is positive, as illustrated by the smallness of the $p$-value and the magnitude of the correlation coefficient, which at about $75 \%$ is relatively high. The association is further illustrated by Figure 8 below, which plots unemployment ratio on the $y$-axis against average monthly per capita expenditures over rank-ordered expenditure quantile incremental range of equal size, each accounting for about one-twentieth of total population. Small values of monthly per capita expenditure (the lowest expenditure percentile or high poverty rates) are associated with high unemployment ratios. It is worth pointing out the curvilinear shape and the convexity of the curve, whose second derivative is positive. The curvilinear shape suggests a non linear relationship, implying that there may be other congruent factors affecting the dynamics of poverty, particularly at the higher end of the distribution of income.

\section{Figure 8: Distribution of Unemployment Ratios Across Monthly Per Capita Income Percentile (in LVL)}

\footnotetext{
${ }^{32}$ To the extent that pensions may be viewed as proportional to workers' salaries and after tax wage income in the form of a capital-reserve system for redistribution over the lifetime of an individual during retirement periods, unemployment, salary and wage income may be the key labor market correlates of poverty in Latvia.
} 


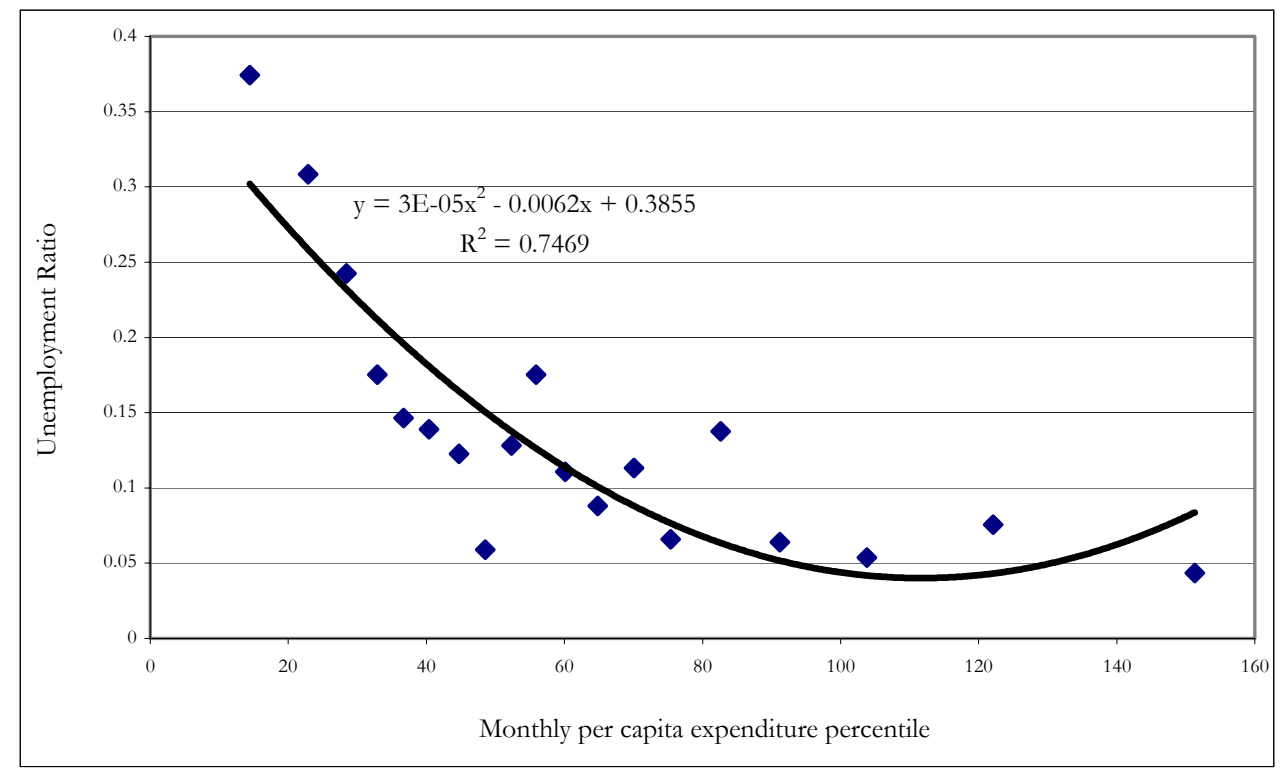

Source: Latvia Household Budget Survey 2000.

\section{Determinants and Correlates of Poverty in the Late 1990s}

In this section, we use a probit model in a standard form with binary outcomes to investigate the determinants of poverty in the late 1990s. This model falls within the family of generalized linear models, with the exception that the response is not continuous, but discrete. This discrete response is related to exogenous variables through a non-linear probit link function expressed as follows:

$$
\eta=\Phi^{-1}(\mu)
$$

where $\Phi^{-1}$ is the inverse of the standard normal cumulative distribution function (CDF). The transformation to the CDF is important for welfare inference because of its non-decreasing shape. In the general linear model, the response $\eta$ is expressed as a function of linear predictor variables $x_{1}, x_{2}, \cdots, x_{k}{ }^{33}$ This specification is very useful for studying events with binary outcomes, and can be quite appealing for investigating the determinants of poverty when the distribution follows a binomial process, with the response taking values 1 for non poor and 0 for poor households or individuals. ${ }^{34} \mathrm{We}$ assume that the observations are a random sample of unreplicated data with dichotomous response, accounting for the widespread nature of poverty illustrated notably by the relatively large poverty incidence. Hence, the continuous response derived directly from the aggregated household per capita

\footnotetext{
${ }^{33}$ For further details on probit models, see Greene (1997).

${ }^{34}$ This model can also be extended to model events with polychotomous outcomes, depending on the nature of the transformation imposed to the initial distribution of income, which is continuous and has the positive real line $\left(y_{h}^{*} \in \mathfrak{R}^{+}\right)$ as support.
} 
expenditures $y_{h}^{*}$ is transformed into a dichotomous response variable $\tilde{y}_{h}$ with binary outcomes taking two values $\left(\tilde{y}_{h} \in\{0,1\}\right)$, with

$$
\tilde{y}_{h}=1, \text { if } y_{h}^{*}>l, 0 \text { otherwise }
$$

where $l$ is the poverty line and $y_{h}^{*}>l$ represents all households or individuals classified as non-poor. It is common to express these models in probability form for ease of inference. Hence, and in a related vein, the probability of being non-poor which corresponds to $\widetilde{y}_{h}=1$, is derived using the following equation:

$$
P_{r}\left(\tilde{y}_{h}=1\right)=\Phi\left[\sum_{k=1}^{K} \beta_{k} x_{k}\right]
$$

Actually, we are more interested in the event probability of being poor. That event is the complement of the event probability of being non poor in the binomial distributional context. Hence, because the two sets are disjoint, and their two events are complementary, the probability associated with the alternative event (being poor) is represented by:

$$
P_{r}\left(\tilde{y}_{h}=0\right)=1-\Phi\left[\sum_{k=1}^{K} \beta_{k} x_{k}\right]
$$

When combined with the estimated probit coefficients $\hat{\beta}_{k}$, the predicted probability can prove even more useful in deriving the marginal effect on the probability of an event. For instance, in the case of Latvia, it may be of particular interest to assess the marginal effect of increased (decreased) unemployment on the estimated probability of being poor, holding others regressors constant. The same principle may be applied in assessing the effects of changing value of age dependency ratio, one of the leading determinants of poverty in most developing countries. This marginal effect is derived by taking the partial derivative of equation (3) with respect to an independent variable $x_{k}$, that is:

$$
\frac{\partial \operatorname{Pr}(Y=1)}{\partial x_{k}}=\Phi\left[\sum_{k=1}^{K} \beta_{k} x_{k}\right] * \beta_{k}
$$

The last Poverty Assessment identified the following as correlates of poverty: mapping of geographical regions to account for spatial effects, socioeconomic groups to capture employment and labor markets dimensions, household ownership of financial and real assets, age dependency ratio and household amenities. ${ }^{35}$ Given that salaries and wages are listed as the main source of income, and particularly for the poor, labor markets and especially unemployment may appear as an important transmission channel through which growth affects poverty. The context in transition economies actually contrasts with other povertystricken regions of the world, and especially Sub-Saharan Africa where the bulk of the poor concentrate in subsistence agriculture and informal sector activities, and where the

\footnotetext{
${ }^{35}$ Age dependency ratio is calculated as the ratio of dependents - the population under age 15 and above 65 - to the workingage population - those aged 15-64.
} 
transmission process from growth to poverty may be significantly different between urban and rural areas. ${ }^{36}$ To account for this specificity of transition economies, and particularly Latvia, we include an estimate of unemployment ratio in the set of regressors, as well as income inequality, which is listed as one of the main causes of rapid increase of poverty in the transition period. We account for this by including in the regressor a proxy for income inequality estimated as the absolute deviation from the median income at the household level.

The model is used sequentially, drawing on the stepwise procedure to investigate the poverty determinants at the national level and across urban and rural areas. The poverty determinants are represented as a function of host of variables, conditioning variables, and the parameters are estimated from the model in each period. In particular, the spatial location and other socioeconomic variables are conditioned upon the poverty rates prior to parameters estimation to account for possible effects of initial conditions and persistence in poverty. Hence, the function $D_{t}(\bullet)$ which captures the determinants of poverty at time $t$ can be represented by the following equation:

$$
D_{t}=f\left(\bullet \mid \hat{P}_{(\alpha, t)}, \hat{\beta}_{t}\right)
$$

where the conditioning variable $\hat{P}_{(\alpha, t)}$ is known, and the objective is to estimate the regression parameters $\hat{\beta}_{t}$, so as to maximize the log of the probit likelihood function. A relatively large number of regressors are considered in the initial model and then gradually reduced through a calibrated stepwise procedure in the process of maximization of the likelihood function. ${ }^{37}$

\section{Empirical Results}

The probit analysis identifies a number of variables as determinants of poverty in Latvia in the late 1990s. These variables include unemployment ratio, household amenities and facilities, ownership of assets and durable goods, and income inequality, spatial location of households, and the burden of age dependency. Unemployment ratio appears to be strong and consistently significant across urban and rural areas. This consistency corroborates previous studies, which supports the correlation between unemployment and welfare in most former Eastern European countries during the first phase of the transition (World Bank [2000a, 2000b]). That first phase was indeed characterized by rapid increase in unemployment, due in part to shrinking demand for labor and high rate of job destruction. And the significance of this variable in the late 1990 s may point to its relative stability over time. ${ }^{38}$

\footnotetext{
${ }^{36}$ For further details on the labor market structure in Sub-Saharan African countries, see Agénor, Izquierdo and Fofack [2002] and for the profile of poverty in Sub-Saharan Africa (Bigman and Fofack [2001]).

${ }^{37}$ For further details on the properties of MLE estimates of probit models, see Greene [1997].

${ }^{38}$ In the early 1990 s, the rate of job destruction in Central Europe averaged 12 to $16 \%$ annually, and open unemployment was in the range of 10 to $15 \%$ in the region, with higher rates recorded in a number of countries (World Bank [2000b]).
} 
Table A.8 in the Annex provides the results of the probit regression at the national level. These results include the regression parameters and corresponding standard errors, ChiSquare statistics and $p$-values. The Table also provides estimates of marginal probabilities. At the national level, the likelihood ratio statistics shows that the model is significantly different from the null or intercept only model. All predictors have estimates significantly different from 0 , as judged by the size of $\hat{\beta}$ relative to the asymptotic standard error, and further by the size of $p$-value which gives the upper bound of Type I error probability. ${ }^{39}$ The most significant predictors include household asset ownership, age dependency ratio, employment status of household head, and socioeconomic group of the household head. Note that the latter has one of the largest marginal effects, which increases even more when the ranking of socioeconomic groups is conditioned upon the poverty mapping to capture a possible interaction effect between socioeconomic group (SEG) and initial conditions of poverty. Though consistent with earlier findings, education level of household heads is not significant at the national level, however. This further corroborates the fact that education may not be a discriminating factor between poor and non poor in Latvia. ${ }^{40}$

The marginal effect associated with the variable SEG on the event probability is about $12 \%$. This suggests that a unit change in this predictor would result in increased event probability of being poor by approximately 12 percent (in absolute terms), holding other predictors constant at their mean values. When this variable is conditioned on the poverty ranking, assigning the largest score to the least poor SEG and the smallest score to the poorest group in a scale of 1-to-5, the marginal effect increases to about $24.7 \%$, suggesting that a unit change in SEG ranking after controlling for welfare status would result in an increased event probability by over $24 \%$. This increase is significant and suggests a possible strong interaction between poverty and sector of employment. It also suggests that the prospects for moving across income groups given that one is poor, are likely to result in high payoffs.

In the transitional context, where movement across sectors is already limited, the probability of such a lateral move may be even smaller for the most vulnerable and poverty-stricken individuals and households, as it may require additional investment in skills acquisition and training. Empirical evidence suggest that despite the significant decline in real wages, as a result of the dramatic fall in output and declining labor productivity, the movement across sectors, from say, contracting firms to growing ones with high prospects for employment creation has not followed (World Bank [2000b]). The stagnation in employment flows, especially in a context of falling real wages may reflect the lack of alternative opportunities to low wage employment.

With a marginal effects of about $28.4 \%$, the burden of age dependency appears as one of the strongest correlates of welfare in Latvia. This marginal effect implies that a unit change in the burden of age dependency would result in increased event probability of being poor by approximately $28 \%$ (in absolute terms), ceteris paribus. The burden of age dependency is correlated with household size and structure, which have been identified as strong correlates of poverty in most transition economies. For instance, investigating the determinants of poverty in Eastern Europe and Former Soviet Union, it was found that the headcount index,

\footnotetext{
${ }^{39}$ Type I error probability here refers to non-poor individuals and households that are classified as poor.

${ }^{40}$ Also, this may reflect the high level of public investment in economic and social infrastructure during the socialism era where education was mandatory for all, resulting in high enrollment and literacy rates. This is certainly one of the legacies of the pre-transition era, and a challenge will be to sustain high enrollment and literacy rates over time.
} 
which was about $19.5 \%$ for households with no elderly members aged 65 and above increased to $56.8 \%$ for households with at least three elderly members in Hungary. Similar results were derived for other countries (Braithwaite, Grootaert and Milanovic [2000]). However, household size and composition in Transition Economies are markedly different from that in other developing countries, particularly Sub-Saharan African countries, which have higher dependency ratios; and it may be worth investigating how the changing household structure interplays with poverty in the medium to long run. ${ }^{41}$

Geographical regions (to account for spatial effects), household amenities, household ownership of assets and durable goods, and unemployment are also significant. These correlates have large Chi-Square and their estimated parameters are significantly different from zero at the $95 \%$ confidence level (see Table A.8 in Annex). In particular, the unemployment ratio and its quadratic form are strongly significant with low standard errors for their parameters. ${ }^{42}$ The significance of the quadratic form further emphasizes the preeminence of job creation and promotion of growth strategies with high employment generating opportunities, which call for significant reduction in the time lag between output growth and employment growth, however. Yet evidence from other transition economies suggest that output recovery have not always led to immediate employment recovery; and in some cases, including among the successful reformers, the lag has been quite long (World Bank [2000b]). ${ }^{43}$ The reduction in lag, and hence increased job creation and employment growth will depend on the speed, and successful implementation of reforms and labor market adjustments, to among other things achieve flexibility and movements across sectors.

The significance of the quadratic expression further supports the non linear relationship between unemployment and poverty. This non linearity could reflect the persistence of a number of structural distortions on the labor market, especially in urban areas where the non linear relation is more pronounced (Figure 8$).{ }^{44}$ The non linear pattern and logistic shape of the urban probability, which is uniformly less than 5\% over the support of unemployment ratio also reflects the structurally higher rural unemployment rates in Latvia. Though counterintuitive in light of findings from most other developing countries which have higher urban unemployment rates, the result is consistent in Latvia where labor market attachments of household heads and other household members were singled out as key determinants of welfare in urban areas (World Bank [2000a]).

Figure 8: Predicted probability of being poor by unemployment rates

\footnotetext{
${ }^{41}$ Indeed the burden of age dependency is extremely high in Sub-Saharan African countries, where age dependency ratios exceeding 100 are not uncommon, and reflect the relatively large household size. Empirical evidence has shown that it is a strong determinant of poverty (Lipton [1983], Glewwe [1991]).

42 This further supports earlier studies, which found unemployment to be strongly correlated with poverty in Latvia (World Bank [2000a]).

${ }^{43}$ In Hungary for instance, the number of jobs in 1997 was 30\% less than in 1989, despite the rapid recovery of output to its pre-transitional levels. The slow recovery of employment is not specific to Transition Economies, however; evidence suggest that the adjustment process leading to the reduction in time lag exceeded 15 years in the case of Spain.

${ }^{44}$ These distortions, most of which are the legacy of the socialism era, include overstaffing of state owned enterprises, labor market regulation and wages rigidities, and especially at the higher income bracket range. However, as part of the reform process, Latvian authorities have been implementing a number of adjustments to the labor market, particularly to achieve more flexibility in wage setting. This has particularly been reflected in the more rapid increase in wages for skilled workers with higher education, by over 23\% between 1997 and 2000 (see Republic of Latvia, 2003).
} 


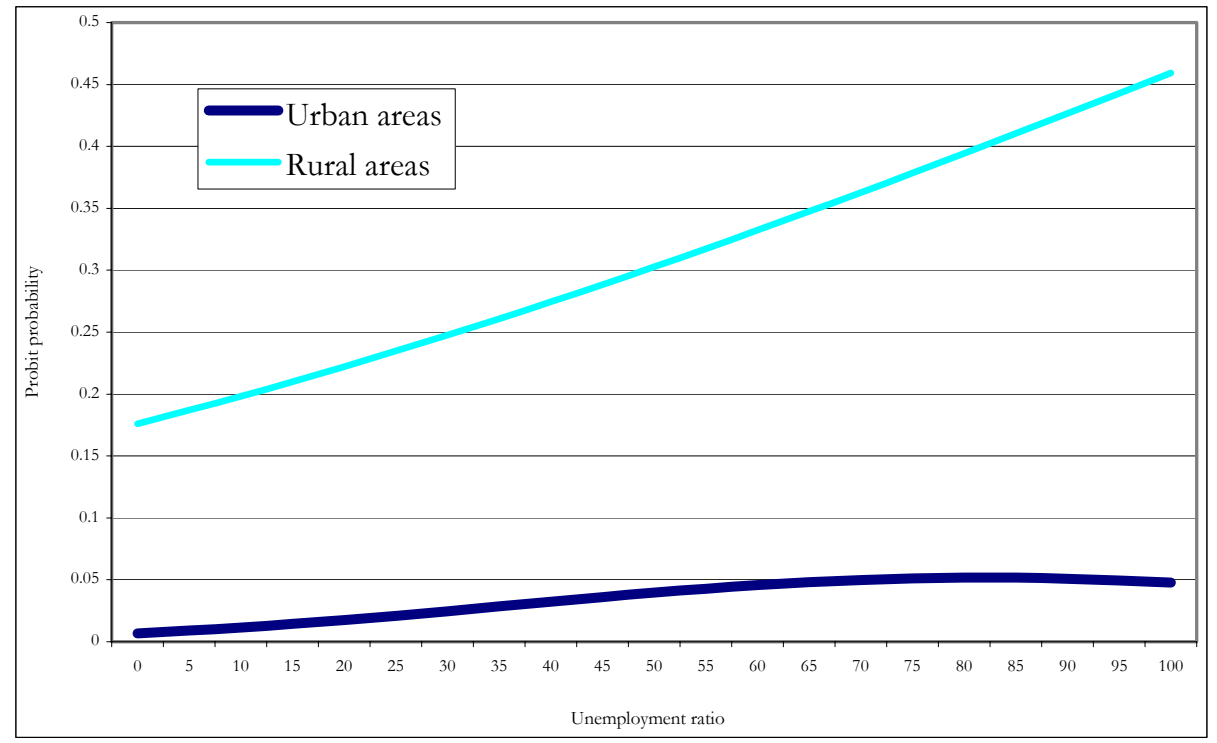

We also investigate the determinants of poverty along geographical lines. When the entire sample is restricted along urban and rural geographical lines, the spatial location of households is a significant determinant of poverty in rural areas, and less so in urban areas where it has a lower marginal effect. The results of the probit analysis are summarized in Table A.9 in the Annex (determinants of poverty in urban areas) and Table A.10 in the Annex (determinants of poverty in rural areas). However, even though the parameter estimates for spatial effects are significantly different from zero at the $95 \%$ level, the scope of the marginal effects associated with these variables is limited. In particular, when the spatial location of households is controlled for, to account for a possible interaction between poverty and geographic regions, the marginal effect increases significantly to over $11 \%$ in rural areas. This relatively large increase and effect on the event probability suggests the existence of a strong interaction and geographical effect on poverty, and possibly expected high payoffs from internal migrations. Nonetheless, the costs of inter-regional migration may be prohibitive for the poor, which have limited assets endowment, and especially in a context of high unemployment, and shortage of supply in the housing market. ${ }^{45}$

In addition to the interaction term between poverty and geographical location of households in rural areas, the "burden of age dependency," "SEG," and the interaction term constructed by conditionally ranking "SEG" to be consistent with the poverty map also produces a relatively large marginal effect on the response probability space. When the "SEG" is taken alone, the marginal effects on the response is about $25 \%$; and when it is combined with the poverty mapping of SEG, the marginal effect increases to over $48 \%$. This result is consistent and suggests that the likelihood of being poor varies considerably across SEG, and the payoffs from moving across socioeconomic groups are likely to be even higher for the poor. ${ }^{46}$

\footnotetext{
${ }^{45}$ Despite ongoing reforms, the housing market is not yet sufficiently flexible to permit easy migration to areas experiencing higher growth in labor demands (Braithwaite, Grootaert and Milanovic [2000]).

${ }^{46}$ For instance, the probability of being poor is very high when the main income source is from "Social Benefits," and poor individuals moving into a different socioeconomic group, that is growth oriented with prospects for employment creation will greatly increase their potential for welfare improvement.
} 
The preeminence of SEG among the key determinants of poverty in Latvia is further illustrated by the significance of "EMPLOY" for employment status of household heads. This correlate has a parameter significantly different from zero at the $95 \%$ level in urban and rural areas. Its marginal effect is in the magnitude of $13 \%$ in rural areas and $11 \%$ in urban areas. ${ }^{47}$ Moreover, the distribution of welfare across employment status of household heads has large variance. While the headcount index is about $14 \%$ at the national level, the poverty rate for unemployed is about $40 \%$, significantly above the rate recorded for the employed income group. The welfare contrast between employed and unemployed was already apparent in the mid 1990s, where the headcount for unemployed then, exceeded 38\% (World Bank [2000a]). The persistence of this contrast in the late 1990s may suggest that the benefits of growth accruing to this vulnerable group were not significant, reflecting the fact that growth may not have led to significant creation of jobs.

In a context where most income is derived from wages and salaries, the significance of unemployment is not counterintuitive. Poverty is in fact directly related to unemployment in urban and rural areas in Latvia. The significance of this regressor is illustrated by Figure 8. The figure provides estimates of the conditional probability of being poor, plotted on the $y$ axis against increasing ratio of unemployment on the $x$-axis, holding other regressors constant at their mean values. The urban probability plot refers to the dark curve; the rural probability plot refers to the heavy and gray curve. The slope of these curves is positive, suggesting that the probability of being poor rises with unemployment ratio. However, for the same unemployment ratio, the event probability of being poor is uniformly higher in rural areas, again, reflecting the urban-rural poverty and unemployment gaps. The probability of being poor ranges from 17 to $45 \%$ in rural areas, and varies between 0 and $5 \%$ in urban areas over the support of unemployment ratio.

When conditioned upon unemployment ratio, the rural predicted probability of being poor is almost linear. It rises almost uniformly for increasing unemployment ratio. The near linear pattern may suggest that the chances of being poor when one is unemployed are higher in rural areas, probably reflecting the limited opportunities and income generating activities there. By contrast, the urban predicted probability has a curvilinear shape with extremely low probability over the support of unemployment. That curvilinear shape is partly illustrated by the widening urban-rural predicted probability gaps, especially towards the end of the support of the hypothesized unemployment ratio, where the gap is about 40 percentage points.

There are other correlates with large marginal effects on the event probability at the regional levels. In particular, these include the burden of age dependency, employment status, housing amenities. Here, we focus on the latter, which as pointed out earlier has one of the largest Chi-square statistics, and has been identified in the past to be significant in Transition Economies (World Bank [2000a]). The parameter estimate of housing amenities variable derived as the sum across all facilities available at the household level is a significant determinant of poverty in urban and rural areas. ${ }^{48}$ In spite of its relatively low marginal effect

\footnotetext{
${ }^{47}$ The significance of this predictor is not specific to Latvia, however. A number of labor market-related variables - head is inactive, unemployed or number of unemployed in households--- have been found to be significant determinants of poverty in Eastern Europe and Former Soviet Union countries in most of the 1990s, reflecting the fact that unemployment has been the most visible signs of the social costs of transition (Braithwaite, Grootaert and Milanovic [2000]).

${ }^{48}$ Facilities and amenities available at the household level include: electricity, water supply, sewerage, toilet, hot water supply, central heating, shower or bath, separate kitchen, gas from network, gas from container, electric oven, and phone line.
} 
on the event probability, its predicted probability curve has a smooth and negative slope when plotted against increasing number of household amenities (Figure 9).

Figure 9: Predicted probability of being poor by increasing scope of housing amenities

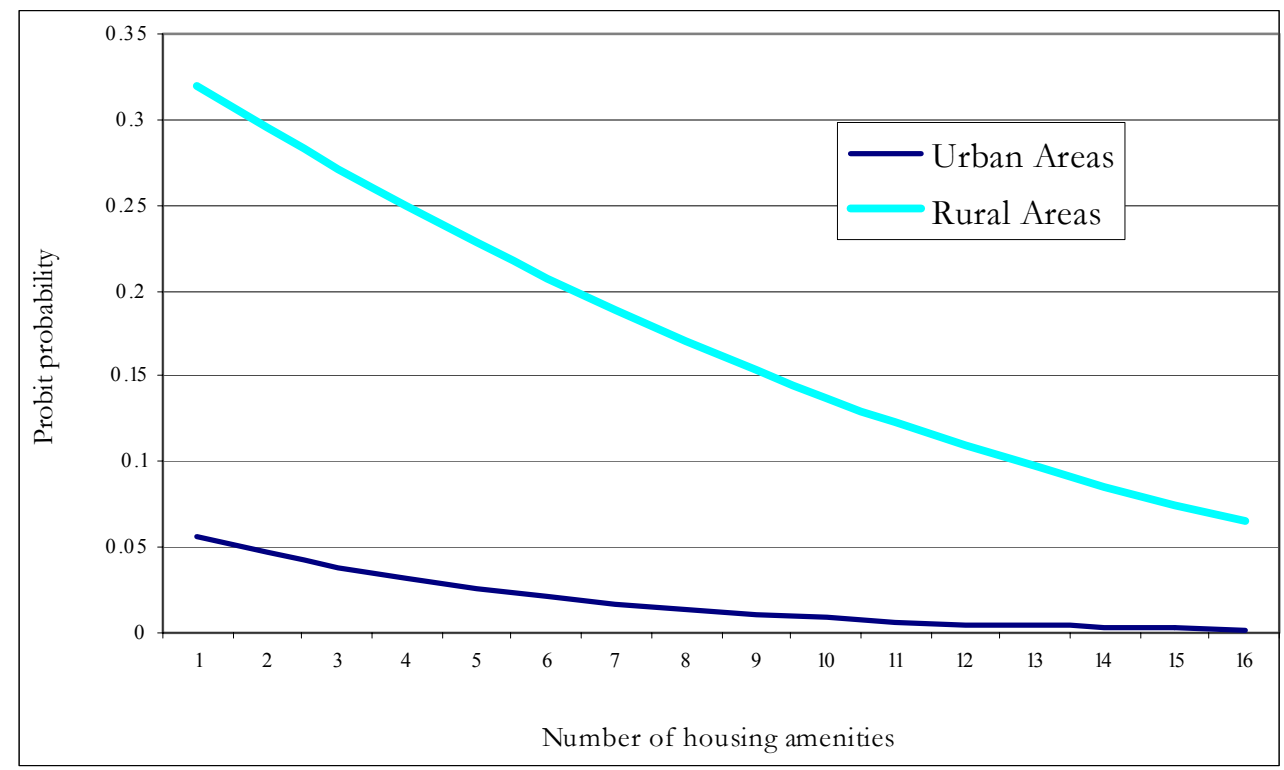

Figure 9 shows that the variable "household amenities" is inversely related to the predicted probability of being poor, which decreases almost linearly as the number of household amenities increases. The declining predicted probability curve is consistent in urban and rural areas. The urban-rural predicted probability gaps are maintained, however. This gap is particularly large at the lower end of housing amenities range. For instance, while the probability of being poor when a household owns only one of the basic housing amenities is about $5 \%$ in urban areas, it is over 30\% in rural areas. As the number of amenities at the household increases, the gap in the predicted probability decreases uniformly, and at the end of the housing amenities range, it is less than 6 percentage points.

The predicted probability of being poor is uniformly less than $6 \%$ over the support of housing amenities in urban areas. It has a wider range in rural areas, illustrated by the steepness associated with the slope of the rural predicted probability curve. The consistently low urban predicted probability curve and steepness of the slope associated with the rural curve for differing assumptions about household ownership of amenities suggests that the distribution of housing facilities is highly unstable in rural areas, where most poor households have access to a limited number of basic amenities. For instance, while over $50 \%$ of households own no more than 5 basic housing amenities in rural areas, urban households are better equipped, with only $5 \%$ of them having less than 5 basic amenities, and over $50 \%$ of them possessing most amenities. 
The increasing significance of housing amenities during the transitional period may reflect the difficulties faced by households, and particularly the poorest ones in their adjustment to market economies. During the pre-transition era where housing amenities (particularly electricity, water supply and gas) were highly subsidized, household access to some of these basic amenities was systematic, and they could not possibly be used as a discriminating factor between poor and non poor. However, the transition to market economy was marked by the end of energy supply credit from Russia and cuts in government subsidies and subsequently, rising housing utility costs and other amenities accrue directly to households, leaving the poverty-stricken ones either energy deficient or with poor facilities. The consistently large gaps in the urban-rural predicted probability may further suggest the preeminence of spatial effects, where the odds of residing in a household with limited facilities are higher in rural areas.

\section{Conclusion and Policy Recommendations}

This paper investigates the dynamics of income inequality and poverty during the recovery phase of the transitional period that characterized the Republic of Latvia in the late 1990s. An attempt is also made to identify the proximate correlates of poverty using a probit model with binary outcomes. The geographical differences, reflected in the significant urban-rural income and poverty gaps, is emphasized. Empirical results show increased income inequality, a significant surge in income growth, particularly in urban areas, and widening urban-rural income gaps between 1997 and 2000. The concentration of income in urban areas and a significant growth of per capita income there, and particularly in the Riga region, during the recovery phase of the transition suggests that income inequality may be driven by wage appreciation at the higher end of the distribution.

With rapidly rising income inequality, the benefits of growth were not uniform across regions and socioeconomic groups. A more rapid decline in poverty rates and improvement of living conditions was recorded in urban areas. Though there was a relative improvement of living conditions across rural areas, owing to a weak increase in income, widespread poverty persisted in a number of geographical regions and among some socioeconomic groups. This is particularly the case for the already poverty-stricken regions of Latgale and Vidzeme, and for the socioeconomic group deriving its main income from social assistance and transfers.

The continued vulnerability of these regions and income groups in the late 1990s is further illustrated by the scope of the poverty gap, which accounts for the average shortfall of income from the poverty line, and the sensitivity of the poverty rates under mild increase of the poverty line. When the poverty line is increased to $35 \mathrm{LVL}$, the deterioration of welfare is significant and poverty is widespread in rural areas, particularly in Latgale where the headcount reaches the level of $33 \%$. Similarly, the poverty rates are more significant among the "Other Social Benefits" group where more than one person out of two has per capita income below $35 \mathrm{LVL}$. When the analysis is confined to rural areas, these rates are even more dramatic, with the incidence of poverty exceeding $70 \%$ in this income group. In addition to the skewness of the growth process, the persistence of poverty and increased vulnerability in a number of regions and among some socioeconomic groups is also exacerbated by the nature of growth, which coexisted with relatively high unemployment, particularly in rural areas. 
Surprisingly, the dramatic increase of poverty among the most vulnerable groups is paralleled with rising social spending. Public assistance in the form of social expenditure and transfers to households increased from $12.5 \%$ to $19.3 \%$ of GDP between 1992 and 1999 . To the extent that this rising pattern of social spending is not paralleled by improved welfare in the target groups and intended beneficiaries, the persistently high depth of poverty among households receiving social benefits and assistance raises the issues of efficiency and targeting of public spending. With aggregate social spending at already high levels, increasing efficiency in public spending allocation and targeting mechanisms may become even more important, especially with Latvia acceding to EU membership, where adherence to the Maastrich treaty, the anchor for macroeconomic stability and growth, is mandatory. ${ }^{49}$

Alternative means for poverty alleviation should be explored, including improved targeting and reduction of leakages in social spending and transfers to the poor, especially in the Latvian context where social transfers are inequality-reducing and welfare-enhancing. Greater emphasis should also be put on increased employment and income generating activities, particularly in rural areas where unemployment appears as one of the most significant determinants of poverty, with the probability of a given household being poor increasing rapidly with the rising unemployment ratio. Other key determinants of poverty include the household dependency ratio, household geographical location, ownership of assets and housing amenities. The latter is particularly significant in rural areas, where rising ownership of housing amenities is inversely related with the probability of being poor.

In spite of the relatively strong level of association between poverty and its identified determinants (the association is partly illustrated by the significance of the probit coefficients, and the smoothness of the estimated probability curves), the latter do not establish causality to poverty. A dual relationship may even exist between poverty and some of these identified determinants. In particular, poor asset endowment, a characteristic of initial conditions and a residual of the pre-socialism era, may be a constraint to income growth and further accumulation, as well as hedging against risks and uncertainty during economic downturns. Similarly, though unemployment appears to be strongly associated with poverty, high poverty rates may continue to exist, even in a context of low unemployment rates. Depending on the wage structure, extremely low wages may simply be considered as disguised unemployment. In that respect, Latvian authorities have been adjusting their minimum wage to account for increased costs of living over time. A possible future research agenda in the areas of growth, labor market and poverty could focus on assessing the causality between unemployment and poverty, particularly investigating the possible causes of the observed non linear pattern. It could also focus on improving the understanding of some of the key characteristics of the poor and constraints to escaping from poverty in the midst of growth, drawing possibly on a combination of household budget and labor force survey data provided by the Latvian Central Statistics Bureau.

\footnotetext{
${ }^{49}$ Under that treaty which is the prevailing framework in the EU and the jurisprudence of the Stability and Growth Pact (SGP), fiscal deficit should not exceed 3 percent of GDP. Together with the goal of a balanced budget in the medium-term, especially against the background of the exchange rate peg of the Lats to the SDR, that stringent ceiling may limit the prospects for continued increase of social transfers for poverty alleviation.
} 


\section{References:}

Agénor Pierre-Richard, A. Izquierdo and H. Fofack (2003). "A Quantitative Macroeconomic Framework for the Análisis of Poverty Reduction Strategies." Forthcoming World Bank Policy Research Working Paper. World Bank, Washington D.C.

Bigman David and Hippolyte Fofack (2000). "Geographical Targeting for Poverty Alleviation: Methodology and Applications." World Bank Regional and Sectoral Studies. The World Bank, Washington D.C.

Braithwaite Jeanine, C. Grootaert and Branko Milanovic (2000). "Poverty and Social Assistance in Transition Countries.” London, New York: St. Martin's Press.

Canagarajah Sudharshan, Dipak Mazumdar and Xiao Ye (1998). "The Structure and Determinants of Inequality and Poverty Reduction in Ghana, 1988-92." World Bank Policy Research Working Paper No. 1998.

Deaton Angus and John Muellbauer (1980). "Economics of Consumer Behavior." Cambridge, UK.: Cambridge University Press.

Fofack Hippolyte (2002). "The Nature and Dynamics of Poverty Determinants in Burkina Faso in the 1990s." World Bank Policy Research Working Paper No. 2847.

Foster, J., Greer, J. and Thorbecke E. (1984). "A Class of Decomposable Poverty Measures." Econometrica, 52, pp. 761-765.

Gassman Franziska (1998). "Who and Where are the Poor in Latvia." UNDP, June 1998 Government of the Republic of Latvia, Social Report 1996-1997.

Glewwe Paul (1991). "Investigating the Determinants of Household Welfare in Côte d'Ivoire." Journal of Development Economics, Vol. 35(2): 307-337.

Greene William H. (1997). "Econometrics Analysis." $3^{\text {rd }}$ Edition. Upper Saddle River, New Jersey, Prentice Hall.

Heady Christopher, Theodore Mitrakos and Panos Tsakloglou (2001). "The Distributional Impact of Social Transfers in the European Union: Evidence from the ECHP”. Discussion Paper No. 356.

International Monetary Fund (2003). "Republic of Latvia, Staff Report for the 2003 Article IV Consultation.” IMF Country Report No. 03/113.

Kakwani Nanak. (1993). "Poverty and Economic Growth with Application to Côte d'Ivoire." Review of Income and Wealth. Series 39 (2). pp. 121-139.

Lipton Michael (1983). "Demography and Poverty." World Bank Staff Working Papers Number 623. World Bank, Washington D.C.

Londono Juan Luis and Miguel Székely (2000). "Persistent Poverty and Excess Inequality: Latin America, 1970-1995.” Journal of Applied Economics, Vol. III, No. 1, pp. 93-134.

Milanovic Branko (1999). "Explaining the Increase in Income Inequality during the Transition." World Bank Policy Research Working Paper No. 1935. World Bank, Washington D.C.

OECD (2003). "Labor Market and Social Policies in the Baltic Countries", OECD Report, Paris, 2003.

Osberg Lars. (1991). "Economic Inequality and Poverty: International Perspectives.” Sharpe.

Ravallion Martin (2001). "Growth, Inequality and Poverty: Looking Beyond Averages." World Development, Vol. 29, No. 11, pp. 1803-1815. 
Ravallion Martin (1992). "Poverty Comparisons: A Guide to Concepts and Methods." Living Standards Measurement Study Working Paper No. 88.

Republic of Latvia (2001). "Labor Force Survey Report." Central Statistical Bureau, Ministry of Finance, Republic of Latvia.

Republic of Latvia (2003). "Ministry of Welfare Social Report." Government of Latvia, Republic of Latvia.

World Bank (1998). “African Development Indicators.” The World Bank, Washington D. C.

World Bank (2000a). "The Republic of Latvia Poverty Assessment." Poverty Reduction and Economic Management Unit (ECSPE) Eastern Europe and Central Asia Region. Report No. 20707-LV, The World Bank.

World Bank (200b). "Making Transition Work for Everyone: Poverty and Inequality in Europe and Central Asia." The World Bank, Washington D.C.

World Bank (2002). "Country Assistance Strategy for The Republic of Latvia." Poverty Reduction and Economic Management Unit (ECSPE) Eastern Europe and Central Asia Region. Report No. 23610-LV, The World Bank, Washington D.C.

World Bank (1998). "World Bank African Development Indicators." The World Bank, Washington D.C.

Zile Roberts and Inna Steinbuka (2001). "Latvia on the way to the European Union." Finance and Development, Volume 38, Number 2. International Monetary Fund. 


\section{Annexes}

Table A. 1: Per Capita Household Income-Based Summary Statistics and Income Inequality Measures (in LVL)

\begin{tabular}{lllllll}
\hline & \multicolumn{2}{c}{ National Level } & \multicolumn{2}{c}{ Urban Area } & \multicolumn{2}{c}{ Rural Area } \\
\hline Point Estimates & $\mathbf{1 9 9 7}$ & $\mathbf{2 0 0 0}$ & $\mathbf{1 9 9 7}$ & $\mathbf{2 0 0 0}$ & $\mathbf{1 9 9 7}$ & $\mathbf{2 0 0 0}$ \\
Mean & 59.55 & 75.33 & 61.49 & 82.35 & 54.59 & 58.11 \\
Median & 50.32 & 61.61 & 51.28 & 63.79 & 48.28 & 54.93 \\
Coefficient of variation (CV) & 953.48 & 2001.1 & 786.46 & 2193.97 & 1314.25 & 968.49 \\
Kurtosis & 560.49 & 1101.62 & 31.05 & 807.18 & 699.69 & 22.05 \\
Skewness & 14.66 & 27.53 & 3.94 & 24.2 & 20.85 & 1.62 \\
Gini Coefficient & 31.6 & 34.8 & 30.32 & 35.14 & 34.81 & 31.41 \\
E(0) & 16.81 & 20.38 & 15.40 & 21.56 & 15.95 & 13.67 \\
E(1) & 18.09 & 27.86 & 16.59 & 29.47 & 25.85 & 17.61 \\
E(2) & 31.62 & 78.20 & 21.62 & 86.43 & 69.33 & 21.91 \\
\hline
\end{tabular}

Figure A. 1: Per Capita Expenditure-based Lorenz Concentration Curves

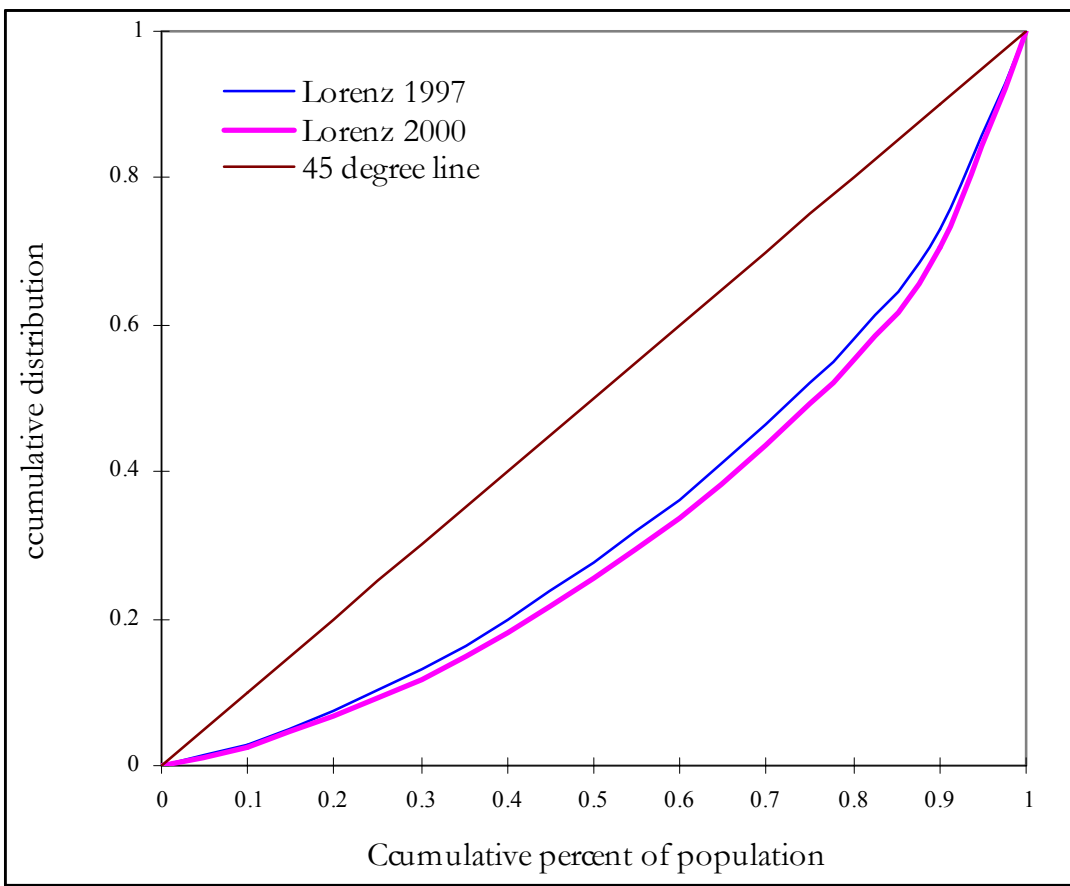


Table A. 2: Distribution of Per Capita Expenditure by Decile (in \%)

Household Budget Survey (1997) Household Budget Survey (2000)

\begin{tabular}{lllllll}
\hline Decile & National & Urban & Rural & National & Urban & Rural \\
1 & 2.9 & 2.5 & 3.9 & 2.4 & 1.5 & 6.2 \\
2 & 4.5 & 3.8 & 6.7 & 4.1 & 2.9 & 8.6 \\
3 & 5.7 & 5.2 & 7.4 & 5.2 & 4.3 & 8.8 \\
4 & 6.7 & 6.4 & 7.7 & 6.3 & 5.5 & 8.9 \\
5 & 7.7 & 7.5 & 8.3 & 7.3 & 6.9 & 9.1 \\
6 & 8.8 & 8.9 & 8.5 & 8.4 & 8.2 & 9.5 \\
7 & 10.1 & 9.6 & 10.9 & 9.8 & 9.7 & 10.0 \\
8 & 11.8 & 12.1 & 11.8 & 11.7 & 11.9 & 11.2 \\
9 & 14.8 & 14.6 & 15.4 & 15.4 & 16.1 & 12.3 \\
10 & 26.9 & 29.4 & 19.4 & 29.3 & 33.1 & 15.3 \\
\hline
\end{tabular}

Table A. 3: Estimates of Income Inequality by Geographical Region

\begin{tabular}{lllll}
\hline & \multicolumn{2}{l}{ Household Budget Survey (1997) } & \multicolumn{2}{l}{ Household Budget Survey (2000) } \\
\hline Regions & Gini & E0 & Gini & E0 \\
Riga & 35.23 & 21.80 & 37.29 & 23.89 \\
Kurzeme & 32.06 & 17.67 & 34.87 & 20.76 \\
Vidzeme & 30.91 & 16.12 & 35.88 & 25.12 \\
Zemgale & 32.78 & 18.54 & 34.62 & 20.38 \\
Latgale & 31.25 & 17.01 & 34.49 & 20.45 \\
Urban & 34.25 & 20.16 & 36.58 & 22.98 \\
Rural & 32.09 & 17.51 & 35.38 & 21.43 \\
National & $\mathbf{3 3 . 8}$ & $\mathbf{1 9 . 6 7}$ & $\mathbf{3 7 . 3}$ & $\mathbf{2 4 . 1 2}$ \\
\hline
\end{tabular}


Figure A. 2: Geographical and Socioeconomic Mapping of Poverty in Latvia

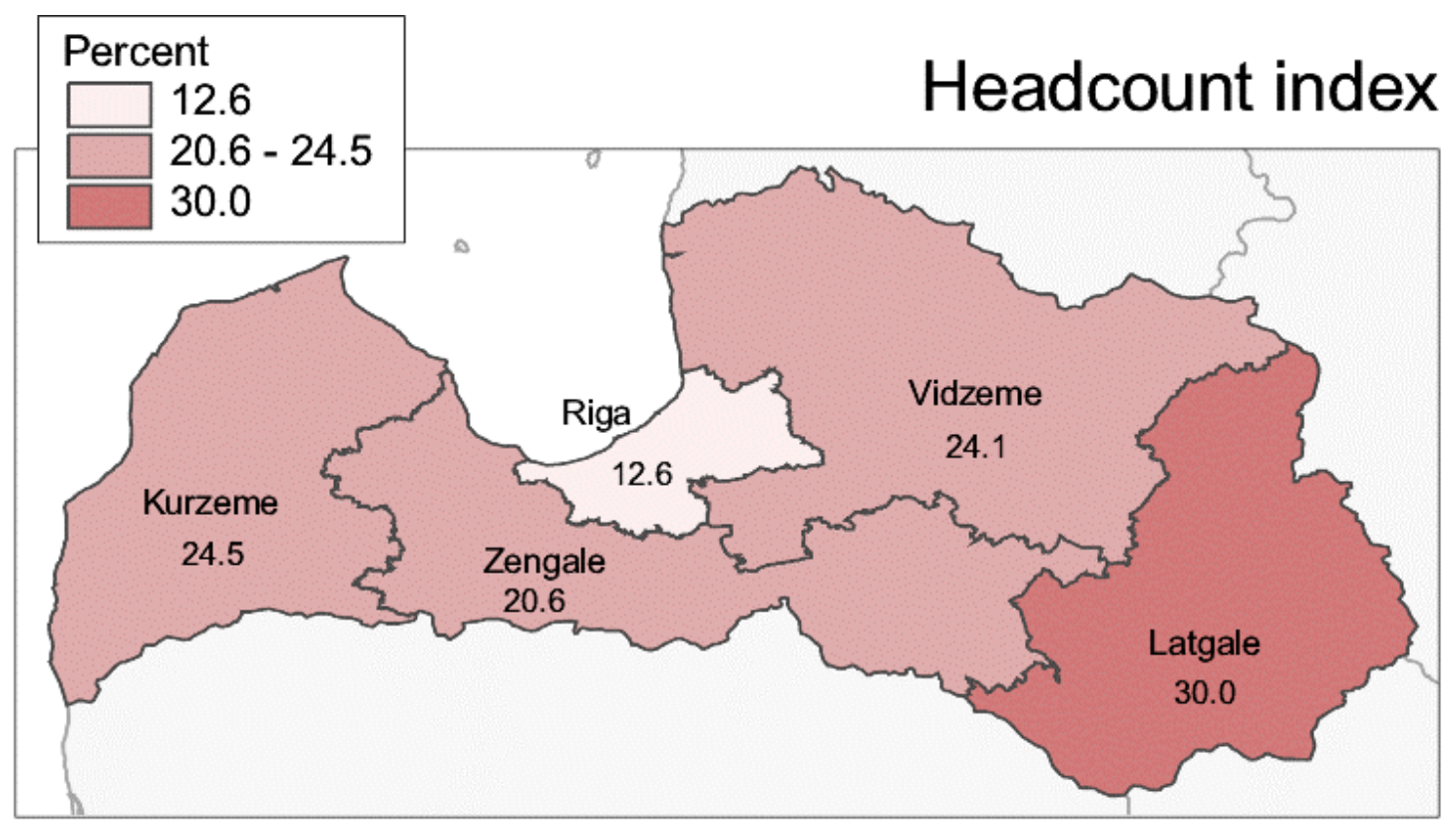

Source: Household Budget Survey (1997).

Table A. 4: Sensitivity Analysis of Poverty Incidence across Socioeconomic Groups in the late 1990s under changing poverty lines in absence of economies of scale $(\theta=1)$

\begin{tabular}{lllllll}
\hline & \multicolumn{3}{c}{ HBS $2000(z=30)$} & \multicolumn{3}{c}{ HBS $2000(z=35)$} \\
\hline Socioeconomic Groups & P0 & P1 & P2 & P0 & P1 & P2 \\
Wage Earners & 12.29 & 3.30 & 1.35 & 17.29 & 4.95 & 2.08 \\
Self-employed & 9.54 & 2.67 & 0.787 & 15.72 & 3.96 & 1.45 \\
Pension & 13.08 & 3.73 & 1.53 & 20.57 & 5.59 & 2.36 \\
Other Social Benefits & 41.42 & 16.52 & 8.79 & 50.39 & 20.82 & 11.42 \\
Other Income & 22.24 & 7.37 & 3.65 & 27.15 & 9.88 & 4.98 \\
Urban & 9.15 & 2.51 & 1.03 & 14.09 & 3.80 & 1.59 \\
Rural & 25.86 & 7.93 & 3.56 & 34.66 & 11.13 & 5.15 \\
Latvia & $\mathbf{1 3 . 9 9}$ & $\mathbf{4 . 0 9}$ & $\mathbf{1 . 7 6}$ & $\mathbf{2 0 . 0 6}$ & $\mathbf{5 . 9 3}$ & $\mathbf{2 . 6 2}$ \\
\hline
\end{tabular}


Table A. 5: Sensitivity Analysis of Poverty Incidence under changing Economies of Scale Across Socioeconomic Groups in the late 1990s

\begin{tabular}{lllllll}
\hline & \multicolumn{3}{c}{ HBS $2000(\theta=1)$} & \multicolumn{3}{c}{ HBS $2000(\theta=.8)$} \\
\hline Socioeconomic Groups & P0 & P1 & P2 & P0 & P1 & P2 \\
Wage Earners & 12.29 & 3.30 & 1.35 & 10.87 & 2.81 & 1.14 \\
Self-employed & 9.54 & 2.67 & 0.787 & 9.54 & 1.83 & 0.415 \\
Pension & 13.08 & 3.73 & 1.53 & 14.82 & 4.02 & 1.63 \\
Other Social Benefits & 41.42 & 16.52 & 8.79 & 41.06 & 14.23 & 7.16 \\
Other Income & 22.24 & 7.37 & 3.65 & 22.69 & 7.79 & 3.79 \\
Urban & 9.15 & 2.51 & 1.03 & 8.91 & 2.36 & 0.09 \\
Rural & 25.86 & 7.93 & 3.56 & 26.27 & 7.63 & 3.31 \\
Latvia & $\mathbf{1 3 . 9 9}$ & $\mathbf{4 . 0 9}$ & $\mathbf{1 . 7 6}$ & $\mathbf{1 3 . 9 5}$ & $\mathbf{3 . 8 9}$ & $\mathbf{1 . 6 5}$ \\
\hline
\end{tabular}

Table A. 6: Sensitivity Analysis of Poverty Incidence across Geographical Regions under changing poverty lines in absence of economies of scale $(\theta=1)$

\begin{tabular}{lllllll}
\hline & \multicolumn{3}{c}{ HBS } & $\mathbf{2 0 0 0}(z=30)$ & \multicolumn{3}{c}{ HBS } & $\mathbf{2 0 0 0}(z=32)$ \\
\hline Geographical Regions & P0 & P1 & P2 & P0 & P1 & P2 \\
Riga & 6.76 & 1.93 & 0.82 & 8.79 & 2.30 & 0.976 \\
Kurzeme & 16.61 & 4.50 & 1.79 & 19.32 & 5.33 & 2.17 \\
Vidzeme & 23.31 & 7.14 & 3.41 & 27.01 & 8.29 & 3.93 \\
Zemgale & 15.14 & 4.36 & 1.85 & 17.92 & 5.14 & 2.20 \\
Latgale & 24.17 & 7.24 & 3.11 & 27.02 & 8.36 & 3.68 \\
Urban & 9.15 & 2.51 & 1.03 & 11.28 & 2.98 & 1.23 \\
Rural & 25.86 & 7.93 & 3.56 & 29.44 & 9.16 & 4.17 \\
Latvia & $\mathbf{1 3 . 9 9}$ & $\mathbf{4 . 0 9}$ & $\mathbf{1 . 7 6}$ & $\mathbf{1 6 . 5 4}$ & $\mathbf{4 . 7 8}$ & $\mathbf{2 . 0 8}$ \\
\hline
\end{tabular}

Table A. 7: Sensitivity Analysis of Poverty Incidence across Geographical Regions under changing poverty lines in absence of economies of scale $(\theta=1)$

\begin{tabular}{lllllll}
\hline & \multicolumn{3}{c}{ HBS } & $\mathbf{2 0 0 0}(z=30)$ & \multicolumn{3}{c}{ HBS } & $\mathbf{2 0 0 0}(z=35)$ \\
\hline Geographical Regions & P0 & P1 & P2 & P0 & P1 & P2 \\
Riga & 6.76 & 1.93 & 0.82 & 11.77 & 2.98 & 1.24 \\
Kurzeme & 16.61 & 4.50 & 1.79 & 22.51 & 6.64 & 2.80 \\
Vidzeme & 23.31 & 7.14 & 3.41 & 29.97 & 10.00 & 4.79 \\
Zemgale & 15.14 & 4.36 & 1.85 & 21.74 & 6.39 & 2.78 \\
Latgale & 24.17 & 7.24 & 3.11 & 32.45 & 10.20 & 4.60 \\
Urban & 9.15 & 2.51 & 1.03 & 14.09 & 3.80 & 1.59 \\
Rural & 25.86 & 7.93 & 3.56 & 34.66 & 11.13 & 5.15 \\
Latvia & $\mathbf{1 3 . 9 9}$ & $\mathbf{4 . 0 9}$ & $\mathbf{1 . 7 6}$ & $\mathbf{2 0 . 0 6}$ & $\mathbf{5 . 9 3}$ & $\mathbf{2 . 6 2}$ \\
\hline
\end{tabular}


Table A. 8: Maximum Likelihood Estimates of Probit Regression Coefficients at the National Level

\begin{tabular}{|c|c|c|c|c|c|c|}
\hline Parameter & DF & Estimate & $\begin{array}{r}\text { Standard } \\
\text { Error } \\
\end{array}$ & $\begin{array}{r}\text { Wald Chi- } \\
\text { Square }\end{array}$ & $\begin{array}{r}\operatorname{Pr}> \\
\text { Chi-Square }\end{array}$ & Marginal effects \\
\hline Intercept & 1 & -1.9935 & 0.0326 & 3728.8323 & $<.0001$ & -1.91903219 \\
\hline Region & 1 & -0.0570 & 0.00124 & 2127.8647 & $<.0001$ & -.054967254 \\
\hline Employ & 1 & 0.1647 & 0.00283 & 3391.9944 & $<.0001$ & .158826433 \\
\hline Seg & 1 & 0.1213 & 0.00409 & 879.2401 & $<.0001$ & .116974173 \\
\hline Totasset & 1 & 0.0593 & 0.000793 & 5591.9881 & $<.0001$ & .057185231 \\
\hline UnemplR & 1 & -0.0144 & 0.000239 & 3642.9893 & $<.0001$ & -.013886464 \\
\hline Howner & 1 & 0.0318 & 0.00285 & 125.0974 & $<.0001$ & .030665942 \\
\hline Nbrooms & 1 & -0.0253 & 0.00274 & 85.8830 & $<.0001$ & -.024397746 \\
\hline Hsfacili & 1 & 0.1012 & 0.000698 & 21022.4097 & $<.0001$ & .097590984 \\
\hline Hsarea & 1 & -0.00158 & 0.000117 & 184.4758 & $<.0001$ & -.001523654 \\
\hline Depratio & 1 & 0.2944 & 0.00577 & 2598.7467 & $<.0001$ & .283901044 \\
\hline Hethnic & 1 & -0.0520 & 0.00135 & 1489.6733 & $<.0001$ & -.0501145565 \\
\hline Devpcinc & 1 & 0.0322 & 0.000230 & 19531.4817 & $<.0001$ & .031051677 \\
\hline Unemplsq & 1 & 0.000072 & $2.602 \mathrm{E}-6$ & 767.8063 & $<.0001$ & $6.94323 \mathrm{E}-05$ \\
\hline Regpov & 1 & 0.0934 & 0.00165 & 3203.6001 & $<.0001$ & .090069149 \\
\hline Segpov & 1 & 0.2567 & 0.00627 & 1677.7980 & $<.0001$ & .24754551 \\
\hline Heducpov & 1 & 0.0736 & 0.00198 & 1386.9324 & $<.0001$ & .070975261 \\
\hline
\end{tabular}

Table A. 9: Maximum Likelihood Estimates of Probit Regression Coefficients (Urban Areas)

\begin{tabular}{llrrrrr}
\hline Parameter & DF & Estimate & $\begin{array}{r}\text { Standard } \\
\text { Error }\end{array}$ & $\begin{array}{r}\text { Wald } \\
\text { Chi-Square }\end{array}$ & Pr $>$ ChiSq & $\begin{array}{r}\text { Marginal } \\
\text { Effects }\end{array}$ \\
\hline Intercept & 1 & 0.3633 & 0.0236 & 237.2356 & $<.0001$ & .359957268 \\
Region & 1 & -0.0444 & 0.00157 & 799.6482 & $<.0001$ & -.043991474 \\
Hedulev & 1 & -0.0399 & 0.00271 & 217.5486 & $<.0001$ & -.039532879 \\
Employ & 1 & 0.1151 & 0.00353 & 1061.6135 & $<.0001$ & .114040962 \\
Totasset & 1 & 0.0681 & 0.00110 & 3849.1868 & $<.0001$ & .06747341 \\
UnemplR & 1 & -0.0205 & 0.000286 & 5151.0090 & $<.0001$ & -.020311379 \\
Howner & 1 & -0.0592 & 0.00377 & 245.6457 & $<.0001$ & -.058655299 \\
Hsmateri & 1 & 0.0179 & 0.00416 & 18.6241 & $<.0001$ & .017735302 \\
Nbrooms & 1 & 0.0441 & 0.00492 & 80.5597 & $<.0001$ & .043694235 \\
Hsfacili & 1 & 0.0877 & 0.00130 & 4553.6619 & $<.0001$ & .08689307 \\
Hsarea & 1 & -0.00348 & 0.000226 & 238.6001 & $<.0001$ & -.00344798 \\
Depratio & 1 & 0.2025 & 0.00780 & 673.1773 & $<.0001$ & .200636792 \\
Hethnic & 1 & -0.0584 & 0.00179 & 1062.4591 & $<.0001$ & -.05786266 \\
Devpcinc & 1 & 0.0379 & 0.000386 & 9629.9461 & $<.0001$ & .037551281 \\
Unemplsq & 1 & 0.000125 & $3.066 \mathrm{E}-6$ & 1661.6803 & $<.0001$ & .00012385 \\
Regpov & 1 & -0.0145 & 0.00262 & 30.6587 & $<.0001$ & -.014366585 \\
\hline
\end{tabular}




\section{Table A. 10: Maximum Likelihood Estimates of Probit Regression Coefficients (Rural Areas)}

\begin{tabular}{llrrrrr}
\hline Parameter & DF & Estimate & $\begin{array}{r}\text { Standard } \\
\text { Error }\end{array}$ & $\begin{array}{r}\text { Wald } \\
\text { Chi-Square }\end{array}$ & Pr $>$ ChiSq & $\begin{array}{r}\text { Marginal } \\
\text { Effects }\end{array}$ \\
\hline Intercept & 1 & -3.8465 & 0.0523 & 5412.7469 & $<.0001$ & -3.109162 \\
Region & 1 & -0.0690 & 0.00223 & 957.3477 & $<.0001$ & -.05577335 \\
Employ & 1 & 0.1625 & 0.00436 & 1392.5701 & $<.0001$ & .131350285 \\
Seg & 1 & 0.3077 & 0.00670 & 2109.0736 & $<.0001$ & .248716817 \\
Totasset & 1 & 0.0434 & 0.00119 & 1322.6463 & $<.0001$ & .03508063 \\
UnemplR & 1 & -0.00828 & 0.000112 & 5489.5225 & $<.0001$ & -.006692802 \\
Howner & 1 & 0.1146 & 0.00459 & 623.7467 & $<.0001$ & .092632263 \\
Nbrooms & 1 & -0.0519 & 0.00339 & 234.3306 & $<.0001$ & -.04195126 \\
Hsfacili & 1 & 0.0692 & 0.00111 & 3854.9096 & $<.0001$ & .055935014 \\
Hsarea & 1 & 0.00220 & 0.000143 & 235.5086 & $<.0001$ & .001778281 \\
Depratio & 1 & 0.3598 & 0.00862 & 1742.7064 & $<.0001$ & .290829739 \\
Hethnic & 1 & -0.0535 & 0.00209 & 653.6806 & $<.0001$ & -.043244555 \\
Devpcinc & 1 & 0.0280 & 0.000308 & 8287.2927 & $<.0001$ & .022632664 \\
Regpov & 1 & 0.1422 & 0.00242 & 3452.0930 & $<.0001$ & .114941603 \\
Segpov & 1 & 0.5897 & 0.0103 & 3306.6463 & $<.0001$ & .476660081 \\
Heducpov & 1 & 0.0838 & 0.00300 & 778.7670 & $<.0001$ & .067736332 \\
\hline
\end{tabular}

